\title{
Crustal seismic structure and anisotropy of Madagascar and southeastern Africa using receiver function harmonics: interplay of inherited local heterogeneities and current regional stress
}

\author{
E. Tsang-Hin-Sun ${ }^{\oplus},{ }^{1,2}$ M. Evain ${ }^{\odot}, 1$ J. Julia ${ }^{\odot}, 3$ G. Lamarque ${ }^{\oplus 1,2}$ and P. Schnurle ${ }^{\oplus 1}$ \\ ${ }^{1}$ Ifremer, Marine Geosciences, Centre de Brest, CS 10070, 29280 Plouzane, France. E-mail: mikael.evain@ifremer.fr \\ ${ }^{2}$ Institut Universitaire Européen de la Mer (IUEM), Laboratoire Geosciences Ocean, Université de Bretagne Occidentale (UBO), UMR 6538, 29280 \\ Plouzané, France \\ ${ }^{3}$ Departamento de Geofisica, Universidade Federal do Rio Grande do Norte, Natal, RN CEP 59078-970, Brazil
}

Accepted 2021 March 24. Received 2021 March 18; in original form 2020 February 5

\begin{abstract}
SUMMAR Y
This study investigates the seismic structure and anisotropy in the crust beneath Madagascar and southeastern Africa, using receiver functions. The understanding of seismic anisotropy is essential for imaging past and present deformation in the lithosphere-asthenosphere system. In the upper mantle, seismic anisotropy mainly results from the orientation of olivine, which deforms under tectonic (fossil anisotropy) or flow processes (in the asthenosphere). In the crust, the crystallographic alignment of amphiboles, feldspars (plagioclase) or micas or the alignment of heterogeneities such as fractures, add to a complex geometry, which results in challenges to understanding the Earth's shallow structure. The decomposition of receiver functions into backazimuth harmonics allows to characterize orientations of lithospheric structure responsible for azimuthally varying seismic signals, such as a dipping isotropic velocity contrasts or layers of azimuthal seismic anisotropy. By analysing receiver function harmonics from records of 48 permanent or temporary stations this study reveals significant azimuthally varying signals within the upper crust of Madagascar and southeastern Africa. At 30 stations crustal anisotropy dominates the harmonics while the signature of a dipping isotropic contrast is dominant at the remaining 18 stations. However, all stations' backazimuth harmonics show complex signals involving both dipping isotropic and shallow anisotropic contrasts or more than one source of anisotropy at shallow depth. Our calculated orientations for the crust are therefore interpreted as reflecting either the average or the interplay of several sources of azimuthally varying signals depending of their strength. However, comparing information between stations allows us to draw the same conclusions regionally: in both southern Africa and Madagascar our measurements reflect the interplay between local, inherited structural heterogeneities and crustal seismic anisotropy generated by the current extensional stress field imposed by the southward propagation of the East-African Rift System. A final comparison of our crustal orientations with SKS orientations attributed to mantle deformation further probes the interplay of crustal and mantle anisotropy on SKS measurements.
\end{abstract}

Key words: Composition and structure of the continental crust; Africa; Seismic anisotropy; Dynamics of lithosphere and mantle.

\section{INTRODUCTION}

Seismic anisotropy, the dependence of seismic wave velocity on direction, occurs at various depth ranges in the Earth's interior and is a critical tool to understand its structure and past to present deformation processes. In the upper mantle, seismic anisotropy usually arises from the crystallographic preferred orientation of olivine in response to large-scale deformation produced by tectonic processes (Silver \& Chan 1988; Silver \& Chan 1991; Savage 1999). In the crust, the presence of seismic anisotropy strongly depends on the mineralogy at depth and its interpretation is more often ambiguous. In the lower crust, amphiboles and feldspars(plagioclase) are the main minerals responsible for seismic anisotropy although the alignment of micas could contribute as well (Sherrington et al. 2004). Unlike the olivine in the mantle, minerals from the crust do not necessarily align their fast axis in the direction of shearing, which yields a complex pattern of anisotropy. 


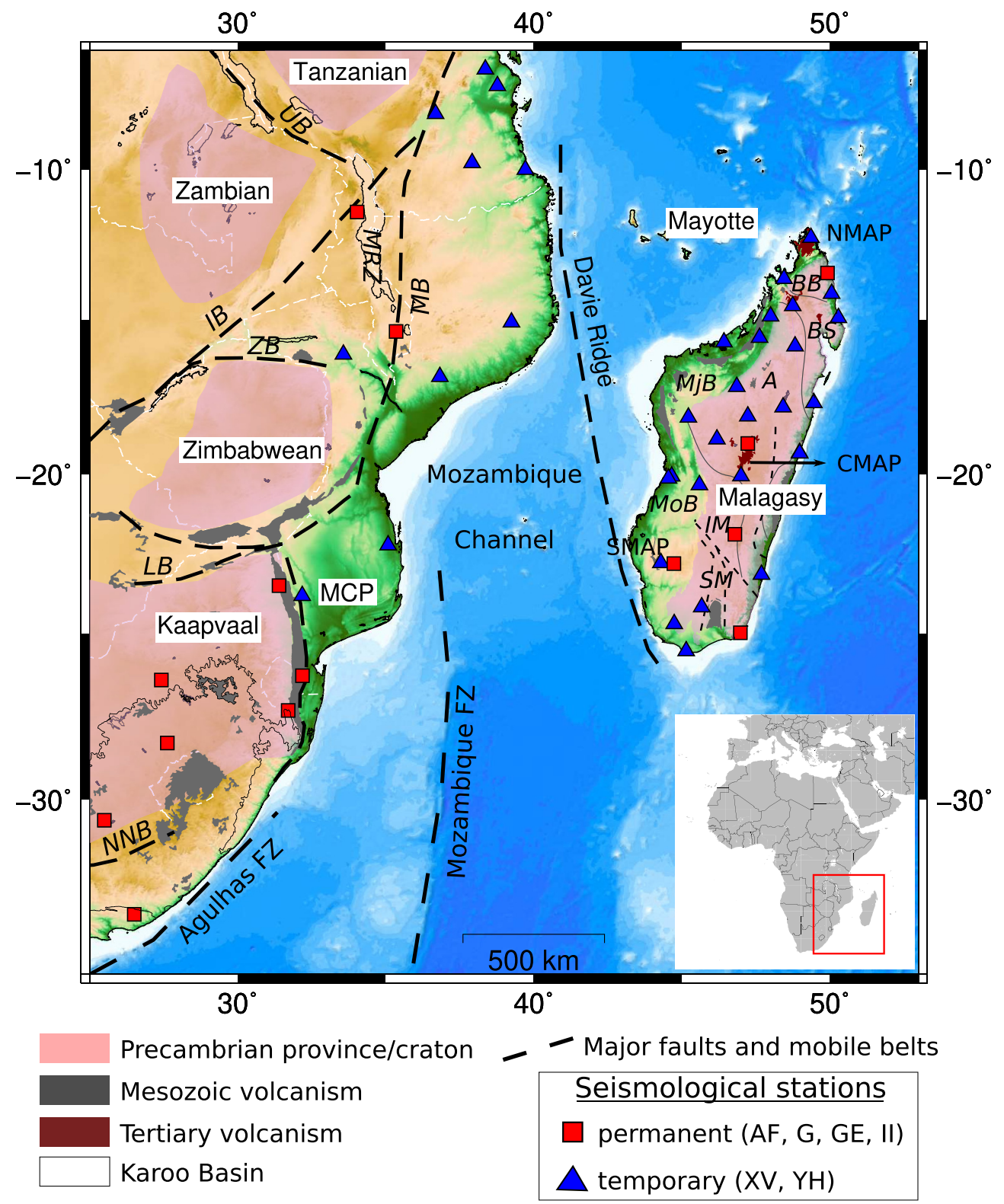

Figure 1. Simplified geodynamical context of the study area and location of the broad-band seismic stations used in the analysis. In Africa: IB, Irumide belt; LB, Limpopo belt; MB, Mozambique belt; MCP, Mozambique Coastal Plain; MRZ, Malawi Rift Zone; NNB, Namaqa-Natal belt; UB, Ubendian belt; ZB, Zambezi belt. In Madagascar; thin dotted lines indicate the major shear zones while thin solid lines delimit the major geological domain; A, Antananarivo block; BB, Bemarivo belt; BS, Betsimisaraka suture; CMAP, Central Madagascar alkaline province; MjB, Mahajanga basin; MoB, Morondava basin; NMAP, Northern Madagascar Alkaline province; SMAP, southern Madagascar Alkaline Province; SM, southern Madagascar.

Finally, in the shallow crust, the alignment of cracks and fractures with the principal stress is the dominant source of azimuthal anisotropy (e.g. Crampin 1978; Boness \& Zoback 2006). The splitting of SKS phases is a classical indicator of azimuthal seismic anisotropy in the upper mantle and is usually interpreted in terms of fossil deformation imprinted into the lithosphere (e.g. Silver \& Chan 1991) or flow in the asthenosphere induced by the current plate motion (e.g. Vinnik et al. 1992; Gao et al. 1994; Becker 2008). In complex geodynamical systems, this proved to be more challenging leading to ambiguous understanding of the mantle fabrics and its underlying evolution (e.g. Vinnik et al. 1995; Silver et al. 2001). One explanation could possibly reside in the contribution from the crust that is often neglected although gneiss and schists in both amphibolite and granulite metamorphic facies could significantly contribute to the splitting of shear waves (Barruol \& Mainprice 1993; Lamarque \& Piana Agostinetti (2020)).

In Madagascar (Fig. 1), for instance, shear wave splitting results are complex and could involve several sources of anisotropy but their respective depth are still poorly constrained. In the southern part, fast polarization orientations roughly align with large Precambrian shear zones, suggesting fossil anisotropy in the lithosphere (Reiss et al. 2016; Ramirez et al. 2018). In the northern and central part of the island, they mismatch the main structural trends but also depart from the direction of the plate motion-driven flow (Ramirez et al. 2018). In the northern part, the interaction of mantle flow (e.g. the plate motion-driven flow, the African Superplume, the Comoros mantle flow) was proposed to 
explain general NE-SW orientations, while the composite pattern observed in the centre of the island could result from the upwelling of the asthenosphere (Paul \& Eakin 2017; Ramirez et al. 2018).

Similarly, several sources of anisotropy might explain the SKS splitting measurements under southern Africa. In East Africa, there is a first-order influence of the mantle flow associated with the African Superplume and the Absolute Plate Motion (APM) in the asthenosphere (Reed et al. 2017), while fossil anisotropy in the lithosphere might explain second-order variations along some orogenic belts (Bagley \& Nyblade 2013). Under the Kaapvaal craton, SKS splitting measurements indicated both fossil anisotropy in the lithosphere (Silver et al. 2001, 2004) and shear of the asthenosphere associated with the APM (Vinnik et al. 1995). Under the Limpopo Belt, fossil anisotropy in the lithosphere or APM-related flow in the asthenosphere could generate the observed splitting parameters (Adam \& Lebedev 2012). However, the surface wave analysis of Adam \& Lebedev (2012) provides clear evidence of strong upper crust anisotropy in the Limpopo Belt but also in the Kaapvaal craton which might have experienced N-S micro-fracturing, possibly related to the southward propagation of the East African Rift System (EARS).

In both regions, the lithosphere results from a complex series of tectonic events (Precambrian amalgamation, volcanism). In particular, several rifting episodes, which accommodated the dislocation of Gondwana, fashioned the western and eastern margins of Madagascar or the Tanzania/Mozambique margins. Yet, the state of the lithosphere beneath these extensive structures has been poorly studied. Moreover, the EARS propagates southwards and might reach the Malawi Rift Zone and Mozambique through its western branch (Chorowicz 2005; Calais et al. 2006) while the Mozambique Channel could represent the propagation terminus of its eastern branch (Courgeon et al. 2016; Deville et al. 2018). However, the connection between the EARS and pre-existing structures in the lithosphere beneath southern Africa and Madagascar is not well understood. In this respect, the depth distribution of anisotropy is a valuable tool to understand the relationship between past and present deformation processes at the scale of the lithosphere.

In recent years, $P$-to- $S$ (or Ps) receiver functions (RFs) have been widely used to resolve complex media, such as dipping interfaces and layered anisotropy. Receiver functions represent $P$-to- $S$ conversions at seismic discontinuities and can be expressed into a radial and a transverse component (Langston 1977; Vinnik 1977). The presence of periodic out-of-plane energy on the transverse component might result from anisotropy and/or a dipping velocity contrast at depth. Moreover, an anisotropic or dipping isotropic structure produces periodic variations in backazimuth and polarity reversals of the RFs (e.g. Levin \& Park 1997a,b; Peng \& Humphreys 1997; Savage 1998; SchultePelkum \& Mahan 2014). The decomposition of the radial and transverse RFs into backazimuth harmonics proved to be efficient in separating structure generating azimuthally varying signals from isotropic structures (e.g. Girardin \& Farra 1998; Piana Agostinetti et al. 2008; Bianchi et al. 2010; Audet 2015; Cossette et al. 2016; Park \& Levin 2016; Lamarque \& Julia 2019). The joint analysis of radial and transverse RFs thus provides complementary information about seismic anisotropy in the lithosphere.

This study presents the analysis of backazimuth harmonics of RFs for 48 stations over part of southern Africa and Madagascar and discusses seismic anisotropy in the crust beneath these regions and its implications in terms of past and current deformation processes. The seismic broad-band stations belong to four permanent (AfricaArray network, GEOFON network, GEOSCOPE and IRIS/IDA seismic networks) and two temporary [AfricaArray SE Tanzania Basin Experiment (Nyblade 2010); MACOMO experiment (Wysession \& Wiens 2011)] networks deployed over the African continent and Madagascar for at least a year (Supporting Information Table S1). The main objectives are to investigate (i) the orientation of deformation in the crust around the Mozambique Channel and its coupling with the local or regional stress field; (ii) anisotropy in the Malagasy and southeastern African lithosphere with respect to previous upper mantle studies; (iii) fossil deformation in the lithosphere beneath regions affected by rifting. Our results highlight the significant contribution of upper crustal seismic anisotropy under these regions which needs to be taken into account to understand past and deformation processes in such complex geodynamical context.

\section{TECTONIC SETTING}

The formation of the Western Indian Ocean initiated in the Jurassic period through a complex fragmentation of Gondwana into four continental blocks along three major fracture zones (Fig. 1). In the north, the Davie Ridge is a large transform fault that accommodated the southward displacement of the Madagascar-India-Seychelles block. The Mozambique Fracture Zone accommodated the southward migration of the Antarctica-Australia block with respect to Africa and the opening of the Mozambique basin, while in the south the Falklands-Agulhas Fracture Zone reflects the westward escape of South America (Patagonia). Rayleigh-wave tomography in the Mozambique Channel indicates that seismic anisotropy is in good agreement with the predicted no net rotation plate motion (Mazzullo et al. 2017).

\subsection{Southern Africa}

The southern African lithosphere formed from Precambrian cratons (e.g. the Kaapvaal and Zimbabwean cratons) suturing along Proterozoic orogenic belts (e.g. the Namaqa-Natal Belt, the Mozambique Belt, the Limpopo Belt). In the south, a major part of the Precambrian crystalline basement is covered by the Karoo volcano-sedimentary basin. The latter, opened as a foreland basin along the Namaqa-Natal Belt, is filled by a 3-9-km thick sedimentary succession and partially overlain by eroded basalts of the Karoo Traps. The Kaapvaal craton constitutes the stable Archean basement in southern Africa and its lithosphere was not affected by later tectonic events (such as the Jurassic rifting; e.g. 
Pearson et al. 1995; Carlson et al. 2000; Schmitz et al. 2004). It is underlain by a thick, cold and basic lithosphere and a crustal thickness ranging from 35 to $45 \mathrm{~km}$ (Nguuri et al. 2001; Stankiewicz et al. 2002).

To the north, the EARS developed following the Afar Depression in Ethiopia and extends southward in the Malawi Rift Zone and possibly propagates across Mozambique (Ebinger et al. 1987). The latter is dominated by a thick Cretaceous and Tertiary sedimentary cover to the south (the Mozambique Coastal Plain; MCP) whose basement nature remains debated (Watts 2001; Watkeys 2002; Leinweber \& Jokat 2011; Domingues et al. 2016). Recent results from an active seismic experiment suggest that continental crust is present under the MCP and extends farther southwards in the offshore domain of the North Natal Valley (Moulin et al. 2019).

\subsection{Madagascar}

Madagascar can be divided into two main structural units (Fig. 1). The Precambrian crystalline basement occupies the major central and eastern parts of the island and is composed of several Archean to Neoproterozoic units, reworked during the Jurassic rifting, and Cretaceous and Cenozoic volcanic episodes (Collins 2006; Tucker et al. 2014). The Antananarivo Block, the largest central terrain, amalgamated with the Bemarivo domain to the north and to the Molo, Androyen and Vohibory domains to the south. The Archean Antongil-Masora craton accreted to the east along the Betsimisaraka suture (Fig. 1). Several large, crustal-scale shear zones go through the Precambrian basement of Madagascar, mainly oriented N-S and evidencing the E-W shortening from Pan-African events (Martelat et al. 2000; Collins 2006).

The western part of the island is overlain by large sedimentary basins, initially shaped in the Permo-Carboniferous period and further developed in the Jurassic period when East Gondwana broke up and moved southward along the Davie Ridge (Coffin \& Rabinowitz 1987). The rifting episode created large normal faults, rift basins and typical horst and graben structures in the sedimentary basins (Schandelmeier et al. 2004). Field studies suggested a thick sedimentary cover, especially under the western basins, while recent seismological observations revealed a sediment thickness of $4 \mathrm{~km}$ to the north and up to $10 \mathrm{~km}$ under the Morondava basin (Andriampenomanana et al. 2017; Adimah \& Padhy 2020).

Volcanic rocks from the Cretaceous and the Cenozoic periods can be found at different locations through the island (Besairie 1973). Cretaceous volcanism was associated with the separation from the India-Seychelles-Australia block, as East Gondwana passed over the Marion hotspot (Torsvik et al. 1998) and is currently evidenced along the eastern and western coasts and in the south of the island. The Cenozoic volcanic activity focuses on the northern (Northern Madagascar alkaline Province, NMAP), central (Central Madagascar alkaline Province, CMAP) and southern (Southern Madagascar Alkaline Province, SMAP) parts of Madagascar. Whereas the origin of the Cenozoic volcanism is discussed, passive seismology imaged low-velocity zones beneath the three provinces, suggesting upwelling from the asthenosphere (Andriampenomanana et al. 2017; Paul \& Eakin 2017; Pratt et al. 2017).

\section{EVIDENCE OF AZIMUTHAL ANISOTROPY FROM RECEIVER FUNCTIONS}

\subsection{Receiver functions}

Receiver functions were computed for 48 broad-band, three-component stations selected from six different permanent and temporary seismological networks located in southern and eastern Africa and in Madagascar (Fig. 1). For all stations (temporary and permanent), RFs were computed from direct $P$ waves of teleseismic earthquakes with a moment magnitude $M_{\mathrm{w}}>5.5$ and an epicentral distance between $30^{\circ}$ and $90^{\circ}$. For temporary stations, the data set was complemented by RFs computed from teleseismic $P P$ waves of earthquakes with a magnitude $M_{\mathrm{w}} \geq 6$ and an epicentral distance between $60^{\circ}$ and $130^{\circ}$. The waveforms were extracted 30 before and $150 \mathrm{~s}$ after the expected phase arrival (direct $P$ or $P P$ phase), then corrected for offset and linear trend and tapered and bandpass filtered in the $0.02-2 \mathrm{~Hz}$ range. Finally, horizontal components were rotated into radial and transverse components. Radial and transverse RFs were then computed by iterative deconvolution in the time domain (Ligorria \& Ammon 1999) for a Gaussian filter with a low-pass frequency of $1.25 \mathrm{~Hz}$ (width $a=2.5$ ). Then, the good quality RFs were automatically selected according to the following criteria: (i) the convolution of the RF with the vertical trace reproduces at least 60 per cent of the initial seismogram; (ii) the largest peak in the radial RF is located in the first $1.5 \mathrm{~s}$ and corresponds to the first phase arrival; (iii) the width of the pulses does not exceed $3.5 \mathrm{~s}$. This last criterion was introduced to remove RFs resulting from unstable deconvolution (Schulte-Pelkum \& Mahan 2014). A final manual selection of the RF eliminated only a few outliers.

In order to sum traces originating from variable epicentral distances, a distance moveout correction with respect to a reference slowness of $6.4 \mathrm{~s} \mathrm{deg}^{-1}$ was applied, using the iasp91 earth model (Kennett \& Engdahl 1991). Then, the corrected RFs were stacked into backazimuth bins of $10^{\circ}$ without overlap and without any threshold on a minimum number of traces to be stacked into one bin (Figs 2 and 3 ). These choices were made owing to our limited backazimuth coverage and to avoid that RFs of lesser quality contaminate adjacent bins. A first-order examination of the radial and transverse RFs, plotted as a function of backazimuth revealed that, at most stations, there is significant energy on the transverse RFs. Moreover, some clear polarity reversals can be identified within the first couple of seconds of the signal, suggesting the presence of dipping and/or anisotropic contrasts at upper to mid crustal depths under these stations. We provide two examples to illustrate these trends. At the station TETE (Fig. 2), located in Zimbabwe $\left(33.58^{\circ} \mathrm{E},-16.15^{\circ} \mathrm{N}\right)$, there is a clear polarity reversal at $\sim 3 \mathrm{~s}$, that is visible on the radial and transverse RFs, suggesting intracrustal anisotropy. At station LAHA (Fig. 3), located in Madagascar $\left(50.29^{\circ} \mathrm{E},-14.93^{\circ} \mathrm{N}\right)$, there is significant energy on the transverse RFs, although the pattern in the polarity reversals is less clear. This could result in a high level of 
(a) Radial

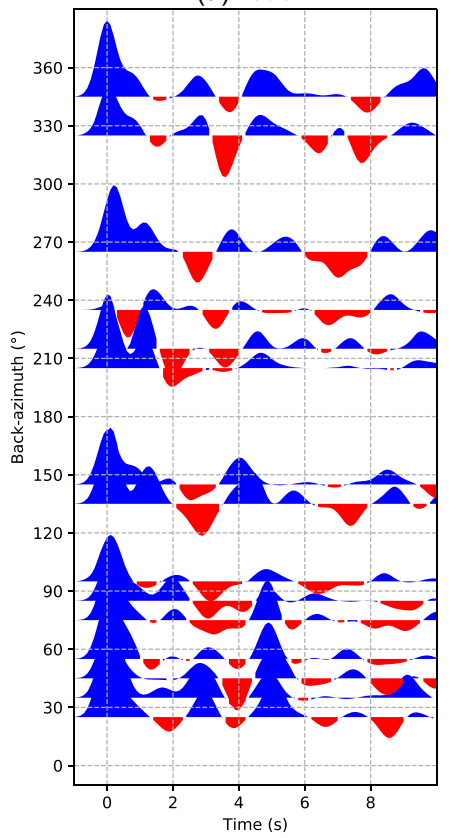

(b) Transverse

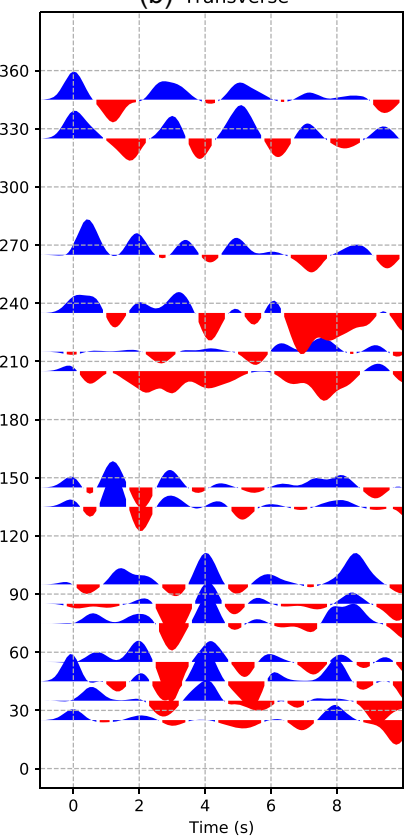

AF-TETE

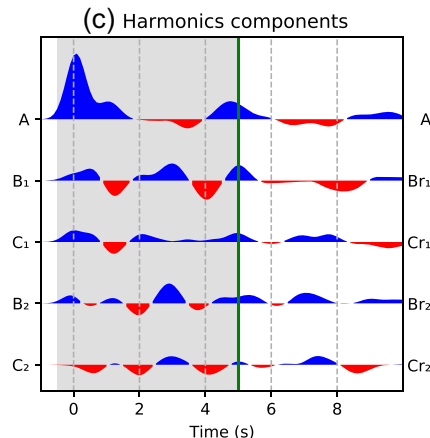

(d) Rotated Harmonics components
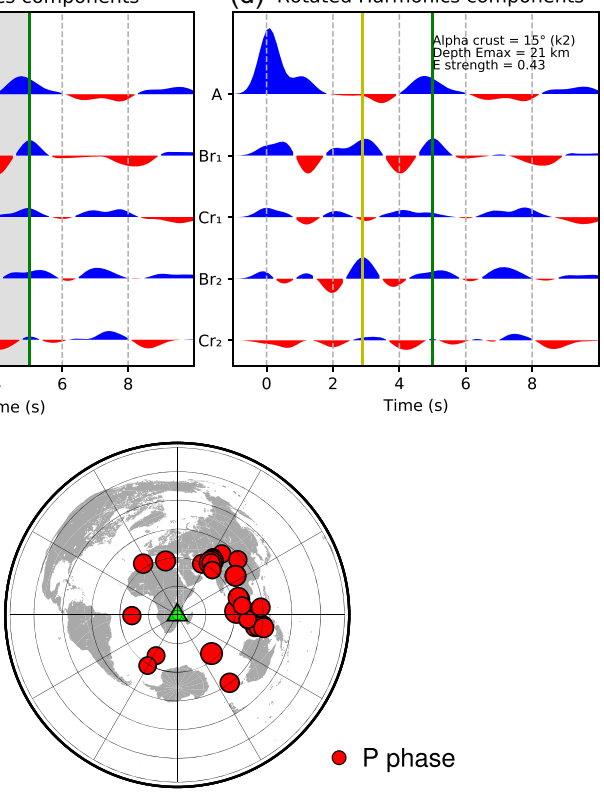

Figure 2. Harmonic decomposition of receiver functions at the station TETE $\left(33.58^{\circ} \mathrm{E},-16.15^{\circ} \mathrm{N}\right)$. (a) Radial and (b) transverse teleseismic receiver functions stacked into $10^{\circ}$ bins; (c) resulting harmonics corresponding to the degrees $k=0(A), k=1\left(B_{1}, C_{1}\right)$ and $k=2\left(B_{2}, C_{2}\right)$; (d) rotated harmonics according to optimum angle that minimizes RMS amplitudes on $C r_{1}$ for the crustal time range (in shaded grey in panel c) and provided in Table 1: degree $k=0(A)$ is repeated then rotated harmonics for degree $k=1\left(\mathrm{Br}_{1}, \mathrm{Cr}_{1}\right)$ and $k=2\left(\mathrm{Br}_{2}, \mathrm{Cr}_{2}\right)$; green line is time conversion of Moho depth, yellow line is time of maximum amplitude among degree- $k$ harmonics. Globe in the bottom right shows location of the teleseismic earthquakes used to compute the initial Rfs.
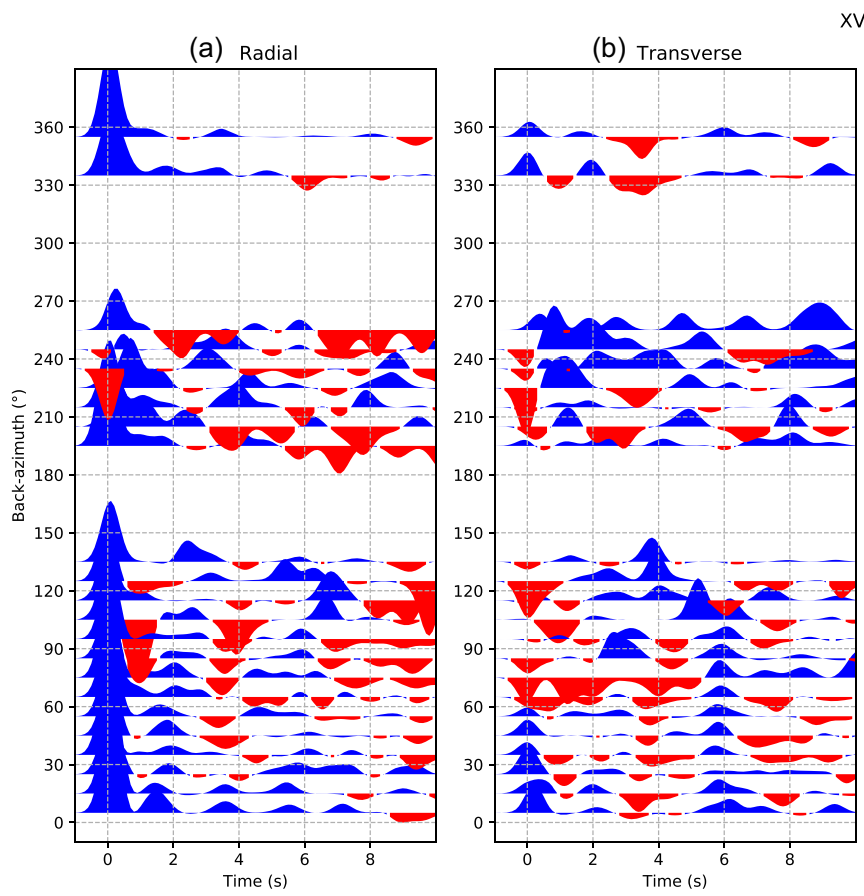

XV-LAHA

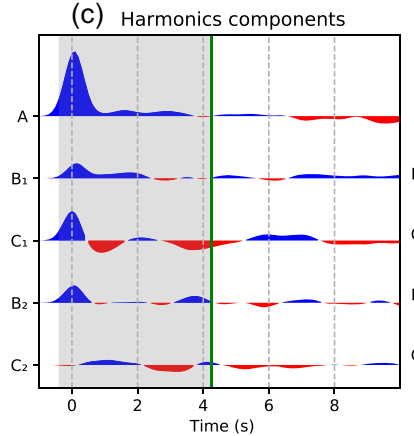

(d) Rotated Harmonics components

Figure 3. Same as Fig. 2 but for the temporary station LAHA, located in Madagascar $\left(50.29^{\circ} \mathrm{E},-14.93^{\circ} \mathrm{N}\right)$. In addition, RFs were also computed for $P P$ phases of teleseismic earthquakes.

uncertainty in the error analysis (see the next section). There is also a clear periodicity at $0 \mathrm{~s}$, possibly followed by another periodic pattern with opposite polarity, which could indicate a dipping isotropic contrast (Schulte-Pelkum \& Mahan 2014). 


\subsection{Backazimuth harmonic decomposition}

Radial and transverse RFs were jointly decomposed into backazimuth harmonics following the method described by Shiomi \& Park (2008) or Bianchi et al. (2010). The harmonic decomposition technique examines the periodicity in radial and transverse RFs as a function of backazimuth. The method assumes that any RF data set can be approximated by the sum of $\cos (k \phi)$ and $\sin (k \phi)$, where $k=0,1,2$ harmonics' degree and $\phi$ is the backazimuth. In matrix form, this is expressed as

$$
\left(\begin{array}{c}
R_{1}(t) \\
\vdots \\
R_{N}(t) \\
T_{1}(t) \\
\vdots \\
T_{N}(t)
\end{array}\right)=\left(\begin{array}{ccccc}
1 & \cos \left(\phi_{1}\right) & \sin \left(\phi_{1}\right) & \cos \left(2 \phi_{1}\right) & \sin \left(2 \phi_{1}\right) \\
\vdots & \vdots & \vdots & \vdots & \vdots \\
1 & \cos \left(\phi_{N}\right) & \sin \left(\phi_{N}\right) & \cos \left(2 \phi_{N}\right) & \sin \left(2 \phi_{N}\right) \\
0 & \cos \left(\phi_{1}+\frac{\pi}{2}\right) & \sin \left(\phi_{1}+\frac{\pi}{2}\right) & \cos \left(2\left(\phi_{1}+\frac{\pi}{4}\right)\right) & \sin \left(2\left(\phi_{1}+\frac{\pi}{4}\right)\right) \\
\vdots & \vdots & \vdots & \vdots & \vdots \\
0 & \cos \left(\phi_{N}+\frac{\pi}{2}\right) & \sin \left(\phi_{N}+\frac{\pi}{2}\right) & \cos \left(2\left(\phi_{N}+\frac{\pi}{4}\right)\right) & \sin \left(2\left(\phi_{N}+\frac{\pi}{4}\right)\right)
\end{array}\right)\left(\begin{array}{c}
A(t) \\
B_{k=1}(t) \\
C_{k=1}(t) \\
B_{k=2}(t) \\
C_{k=2}(t)
\end{array}\right) .
$$

In this system, $A(\mathrm{t})$ corresponds to the degree- 0 harmonic and represents azimuth-invariant structures, that is, contributions from flatlayered isotropic media. The degree-1 components $\left(B_{1}, C_{1}\right)$, represent contrast with a two-lobed periodicity in backazimuth, projected on the $\mathrm{N}-\mathrm{S}$ and $\mathrm{E}-\mathrm{W}$ axis. They are associated with a dipping isotropic interface or azimuthal anisotropy with a plunging axis of symmetry. Conversely, the degree- 2 components represent contrasts producing a four-lobed periodicity with backazimuth, such as azimuthal anisotropy with a horizontal symmetry axis. The system is solved for the five harmonic components by inverting the matrix using singular value decomposition.

\subsection{Mapping interfaces at depth}

As Audet (2015), we chose to retrieve the orientation of a contrast for a specific time/depth range $\left(z_{1}, z_{2}\right)$ by rotating the degree- $k$ ( $k=1$ or $k$ $=2$ ) components $B_{k}$ and $C_{k}$ following eq. (2):

$$
\left(\begin{array}{c}
B r_{k} \\
C r_{k}
\end{array}\right)=\left(\begin{array}{cc}
\cos \alpha & \sin \alpha \\
-\sin \alpha & \cos \alpha
\end{array}\right)\left(\begin{array}{c}
B_{k} \\
C_{k}
\end{array}\right)
$$

and search for an angle $\alpha(0-2 \pi)$ that minimizes the squared amplitudes on the rotated components $\mathrm{Cr}_{k}$ :

$$
\sum_{i=z_{1}}^{z_{2}} C r_{k}(i)^{2}
$$

As a proxy for the depth of the interface in the time/depth range $\left(z_{1}, z_{2}\right)$, we searched among $N$ values of $i$ between $z_{1}$ and $z_{2}$ the maximum of the summed amplitude $A m_{k}(i)$ of the degree- $k$ harmonic components: $A m_{k}(i)=B_{k}(i)^{2}+C_{k}(i)^{2}$.

In the same vein, as a proxy for the strength of the interface in the time/depth range $\left(z_{1}, z_{2}\right)$, we computed the root mean square of the summed amplitude of the degree- $k$ harmonic components $A m_{k}(i)$ :

$\mathrm{RMS}_{k}=\sqrt{\frac{1}{N} \sum_{i=z_{1}}^{z_{2}} A m_{k}(i)}$.

Given that $\mathrm{RMS}_{0}$ is the root mean square of degree-0 harmonic component A and represents the amplitude of flat-layered isotropic structures, this allowed us to scale the amplitude of the degree- 1 or degree- 2 components to the amplitude of the degree- 0 component and quantify the contribution of dipping isotropic/anisotropic contrasts with respect to the contribution from flat-layered isotropic structures.

\subsection{Implementation}

Minimizing the squared amplitude of a particular time/depth range $\left(z_{1}, z_{2}\right)$ implies that signal polarity is not considered in the determination of $\alpha$. Therefore, there is an ambiguity of $\pi$ and $\pi / 2$ respectively on degree- 1 and degree- 2 measures. For degree- 1 components, the angle $\alpha$ should be considered as an azimuth representing either the orientation of the symmetry axis in case of plunging anisotropy or the dipping direction of an isotropic interface. For degree-2 components, diagnostic of horizontal anisotropy, the angles $\alpha$ and $\alpha+90^{\circ}$ can be interpreted as the azimuth of the fast (or slow) axis of symmetry and the slow (or fast) plane normal to it. We concentrated our analysis on the crust, from the surface ( $-0.5 \mathrm{~s}$ ) to the Moho (see Section 3.5). Angles $\alpha$ were estimated on both degree- 1 and degree- 2 components and the dominant (highest RMS) was selected as well as its depth approximation (maximum signal amplitude). It should be noted that while dipping isotropic contrasts have a degree-1 signature, horizontal anisotropy contrast shows up only on degree-2 harmonics, while plunging anisotropy will appear on both harmonic degrees (see Supporting Information Fig. S1). As dipping isotropic contrasts are known to generate a peak of amplitude at $0 \mathrm{~s}$ followed by a second peak of reversed polarity (Schulte-Pelkum \& Mahan 2014; Fig. 3), we automatically conclude this if degree-1 are the dominant harmonics and the depth approximation of $\alpha$ is $0 \mathrm{~km}$, meaning, however, that the true depth of contrasts is 
not approximated in this case. Also, by investigating the whole crustal time range we assume that the layer with the strongest signal will dominate the results in the case of several anisotropic layers. However, we cannot exclude that our calculated angle reflects an average value from different anisotropic layers, or from different types of anisotropy in the case of similar anisotropic strength, or from the combination of dipping isotropic and anisotropic contrasts orientation. Indeed, rotating harmonic components by the dominant angle reveal secondary sources of anisotropy at many stations (see Supporting Information Fig. S3).

\subsection{Moho depth estimation}

At each station, the Moho depth was inferred from published crust analysis results or was estimated using the $H-\kappa$ stacking method (Zhu \& Kanamori 2000) when no data were available. Finally, the Moho depth was extracted from the crust1.0 model (Laske et al. 2013) when the $H-\kappa$ stacking method failed (see Supporting Information Text S2 and Table S2 for further information on the method and results at each station). Practically, as the harmonic components were computed as a function of time, depth values were converted into traveltime according to the iasp91 earth model (Kennett \& Engdahl 1991).

\subsection{Uncertainties calculation}

The uncertainty of $\alpha$ depends on the quality of the RFs (level of noise) and on the backazimuth coverage of the data set. The latter is particularly critical if there is an azimuthal gap oriented normal to the fast axis of symmetry (see Supporting Information Text S1). Uncertainties of our measurements were estimated through Niter $=1000$ bootstrap samples of the initial RF data set before the stacking and harmonics computation. In this way, the uncertainties reflect the level of noise contained in each individual RFs, the level of noise in each bin of summed RFs and the azimuthal coverage. For each iteration, the RF data set was resampled in the bootstrap sense. Then, resampled RFs were stacked into backazimuth bins and the harmonics were computed according to the method described here above. Finally, the best angle was estimated in each layer of interest, according to (2). Hence, uncertainties are defined as the standard error SE of the angle distribution:

$\mathrm{SE}(\hat{\alpha})=\sqrt{\frac{1}{\text { Niter }-1} \sum_{i=1}^{\text {Niter }}\left(\hat{\alpha}_{i}-\bar{\alpha}\right)^{2}}$,

where Niter is the number of bootstrap samples, $\alpha$ denotes the Niter estimates of $\alpha$ from the bootstrap samples and $\bar{\alpha}=\frac{1}{\text { Niter }} \sum_{i=1}^{\text {Niter }} \hat{\alpha}_{i}$ is the mean of the estimates across the bootstrap samples.

\section{RESULTS}

We present our results in Table 1 but Supporting Information Fig. S3 further provides for each analysed seismic station the stacks of radial and transverse receiver functions sorted by backazimuth, their harmonic components and these harmonics rotated according to the estimated angle $\alpha$ provided in this table. Results are also presented on two maps, one for southeastern Africa (Fig. 4) and one for Madagascar (Fig. 5). In the crust, it was shown that the symmetry axis of anisotropy tends to be perpendicular to the foliation (e.g. Brownlee et al. 2017) since foliations are mostly fast plane. For that reason, and to facilitate the interpretation, we plotted the axis parallel to the foliation or the strike in case of a dipping interface, that is $\alpha+90^{\circ}$ for degree- 1 components. As argued by Schulte-Pelkum et al. (2020), this plotting convention generally yields a better agreement with geological structures.

Among the 48 stations analysed in this study 18 (GRM, MZM, POGA, WDLM, ZOMB, VOI, ANLA, BAND, DGOS, LAHA, LONA, MAGY, MAJA, MAPH, MKVA, MOCU, IFAK and WALE) show harmonic components dominated by the signature of a dipping isotropic interface, that is, on rotated components the maximum amplitude in the signal is at $0 \mathrm{~s}$ and this peak is followed a reversed polarity one (depth $=0$ in Table 1). By rotating these harmonic components by their estimated dominant angle $\alpha$, the periodic signature of the dipping interface is emphasized on $\mathrm{Br}_{1}$. One can then clearly observe the presence of secondary sources of anisotropy on $\mathrm{Cr}_{1}$ or degree-2 rotated components at upper crustal depth for all these stations. This secondary signal appears weak for the majority of the stations but it is stronger at stations MZM, BAND, LONA, MAGY, MAPH and IFAK thus interfering on our measurements.

The remaining 30 stations all show harmonics dominated by anisotropic sources at upper to mid crustal depth except at INDI and TETE where the dominant anisotropic contrast is estimated deeper than $20 \mathrm{~km}$. For five stations, the dominant signal is found on their degree-2 harmonics suggesting horizontal anisotropy (TETE, FOMA, SBV, NAPU and MOHO). Similarly a close look at rotated harmonics (particularly $\mathrm{Cr}_{1}$ ) further reveals that for all these stations at least one secondary source of upper crustal anisotropy or possibly of a dipping isotropic interface can be observed. These secondary sources appear non-negligible at stations TETE, MOHO, CNG, VINA, INDI, BATG and BERG.

Overall our analysis clearly highlights the presence of dominant or non-dominant seismic anisotropy at upper crustal level under all the 48 stations studied. It also shows the systematic presence of secondary sources of periodic signal, either from crustal anisotropy or dipping isotropic horizon, in the early time of the $P$-to- $S$ converted coda. Depending on its relative strength compared to the dominant signal a secondary source will potentially interfere in the calculation of the orientation of the dominant source. 
Table 1. Results of the harmonic decomposition method for each station used in the analysis. The crustal thickness was (1) extracted from Andriampenomanana et al. (2017); (2) estimated with the $h-k$ method (Zhu \& Kanamori 2000) applied to the RFs or (3) extracted from the crust1.0 model (Laske et al. 2013). The table is provided in a computer readable format in the Supporting Information.

\begin{tabular}{|c|c|c|c|c|c|c|c|c|}
\hline Station & Network & \#RFs & \# bins in baz & Max gap $\left(^{\circ}\right)$ & $\begin{array}{c}\text { Harmonic } \\
\text { degree }\end{array}$ & $\begin{array}{l}\text { angle }\left(^{\circ}\right) \pm \\
\quad \text { error }\end{array}$ & $\begin{array}{c}\text { Estimated } \\
\text { depth }\end{array}$ & $\begin{array}{c}\text { Moho depth } \\
\quad \text { (\& ref) }\end{array}$ \\
\hline $\mathrm{CNG}$ & $\mathrm{AF}$ & 72 & 26 & 50 & 1 & $20 \pm 6$ & 5 & $37(2)$ \\
\hline GRM & $\mathrm{AF}$ & 199 & 47 & 40 & 1 & $10 \pm 3$ & 0 & $38(2)$ \\
\hline HVD & $\mathrm{AF}$ & 270 & 49 & 30 & 1 & $192 \pm 4$ & 5 & $40(2)$ \\
\hline MOPA & $\mathrm{AF}$ & 137 & 34 & 40 & 1 & $188 \pm 5$ & 2 & $39(2)$ \\
\hline MZM & $\mathrm{AF}$ & 74 & 24 & 70 & 1 & $16 \pm 16$ & 0 & $44(2)$ \\
\hline POGA & $\mathrm{AF}$ & 266 & 43 & 50 & 1 & $7 \pm 12$ & 0 & $37(3)$ \\
\hline SEK & $\mathrm{AF}$ & 261 & 48 & 30 & 1 & $2 \pm 5$ & 4 & $39(2)$ \\
\hline SKRH & $\mathrm{AF}$ & 61 & 33 & 80 & 1 & $134 \pm 9$ & 3 & $28(1)$ \\
\hline TETE & $\mathrm{AF}$ & 33 & 18 & 60 & 2 & $15 \pm 3$ & 21 & $40(2)$ \\
\hline WDLM & $\mathrm{AF}$ & 91 & 28 & 50 & 1 & $175 \pm 66$ & 0 & $40(2)$ \\
\hline ZOMB & $\mathrm{AF}$ & 227 & 47 & 40 & 1 & $16 \pm 10$ & 0 & $40(2)$ \\
\hline FOMA & G & 101 & 48 & 40 & 2 & $24 \pm 25$ & 0 & $36(1)$ \\
\hline SBV & GE & 132 & 48 & 40 & 2 & $7 \pm 22$ & 0 & $31(1)$ \\
\hline VOI & GE & 300 & 74 & 50 & 1 & $104 \pm 30$ & 0 & $41(1)$ \\
\hline $\mathrm{ABPO}$ & II & 130 & 35 & 60 & 1 & $159 \pm 8$ & 2 & $43(1)$ \\
\hline AMPY & $X V$ & 62 & 31 & 70 & 1 & $135 \pm 8$ & 3 & $28(1)$ \\
\hline ANLA & $X V$ & 75 & 33 & 80 & 1 & $285 \pm 66$ & 0 & $43(1)$ \\
\hline ANTS & $X V$ & 52 & 30 & 90 & 1 & $128 \pm 12$ & 3 & $33(1)$ \\
\hline BAEL & $X V$ & 61 & 30 & 90 & 1 & $169 \pm 11$ & 11 & $33(1)$ \\
\hline BAND & $X V$ & 74 & 37 & 50 & 1 & $313 \pm 27$ & 0 & $33(1)$ \\
\hline BARY & $X V$ & 54 & 25 & 70 & 1 & $1 \pm 32$ & 7 & $41(1)$ \\
\hline BATG & $X V$ & 56 & 28 & 120 & 1 & $114 \pm 15$ & 2 & $43(1)$ \\
\hline BERG & $X V$ & 46 & 25 & 80 & 1 & $289 \pm 49$ & 2 & $36(1)$ \\
\hline BITY & $\mathrm{XV}$ & 62 & 30 & 90 & 1 & $2 \pm 9$ & 3 & $43(1)$ \\
\hline BKTA & $\mathrm{XV}$ & 55 & 30 & 60 & 1 & $165 \pm 7$ & 3 & $38(1)$ \\
\hline CPSM & $X V$ & 35 & 23 & 130 & 1 & $343 \pm 6$ & 3 & $33(1)$ \\
\hline DGOS & $X V$ & 25 & 16 & 110 & 1 & $143 \pm 31$ & 0 & $18(1)$ \\
\hline KIRI & $X V$ & 25 & 16 & 110 & 1 & $172 \pm 14$ & 12 & $28(1)$ \\
\hline LAHA & $X V$ & 104 & 42 & 80 & 1 & $71 \pm 78$ & 0 & $33(1)$ \\
\hline LONA & $X V$ & 61 & 34 & 70 & 1 & $120 \pm 8$ & 0 & $28(1)$ \\
\hline MAGY & $X V$ & 33 & 20 & 80 & 1 & $133 \pm 7$ & 0 & $36(1)$ \\
\hline MAHA & $X V$ & 50 & 31 & 90 & 1 & $165 \pm 17$ & 4 & $36(1)$ \\
\hline MAJA & $X V$ & 27 & 22 & 60 & 1 & $152 \pm 13$ & 0 & $36(1)$ \\
\hline MAPH & $\mathrm{XV}$ & 26 & 18 & 110 & 1 & $169 \pm 12$ & 0 & $31(3)$ \\
\hline MKVA & $X V$ & 61 & 31 & 70 & 1 & $100 \pm 46$ & 0 & $36(1)$ \\
\hline MOCU & $X V$ & 49 & 29 & 60 & 1 & $139 \pm 50$ & 0 & $36(2)$ \\
\hline MSGR & $X V$ & 50 & 28 & 60 & 1 & $18 \pm 10$ & 3 & $42(3)$ \\
\hline NAPU & XV & 58 & 33 & 60 & 2 & $98 \pm 19$ & 0 & $42(2)$ \\
\hline TETE & $\mathrm{XV}$ & 34 & 21 & 80 & 1 & $34 \pm 3$ & 2 & $40(2)$ \\
\hline VINA & $X V$ & 52 & 30 & 100 & 1 & $315 \pm 12$ & 13 & $36(1)$ \\
\hline ZAKA & $X V$ & 56 & 32 & 100 & 1 & $131 \pm 18$ & 5 & $43(1)$ \\
\hline ZOBE & $\mathrm{XV}$ & 59 & 32 & 70 & 1 & $351 \pm 6$ & 3 & $46(1)$ \\
\hline CHAL & YH & 84 & 31 & 70 & 1 & $313 \pm 3$ & 6 & 37 (3) \\
\hline IFAK & YH & 69 & 27 & 70 & 1 & $221 \pm 30$ & 0 & 39 (3) \\
\hline INDI & YH & 42 & 22 & 100 & 1 & $12 \pm 23$ & 28 & $37(3)$ \\
\hline MANG & YH & 46 & 25 & 50 & 1 & $80 \pm 17$ & 2 & $21(2)$ \\
\hline МOHO & YH & 16 & 14 & 160 & 2 & $70 \pm 19$ & 0 & $30(3)$ \\
\hline WALE & YH & 94 & 34 & 50 & 1 & $165 \pm 12$ & 0 & $38(2)$ \\
\hline
\end{tabular}

\section{DISCUSSION}

\subsection{Dipping interfaces versus anisotropy in southeastern Africa}

In southeastern Africa, there are clear regional patterns in strength and orientations of our measurements in the crust (Fig. 4). In southern Africa, the strength is high with orientations close to E-W. The strength is much weaker in northern Mozambique but rises again in Tanzania while orientations show more variability.

The homogeneity in strength and orientations is striking in southern Africa despite differences in sources of dominant periodic signal and quite large uncertainties at station WDLM in the central part of the Kaapvaal craton although it belongs to a permanent network. Orientations that deviate the most from this average E-W azimuthal trend in the region are located at stations where interferences from a secondary source 


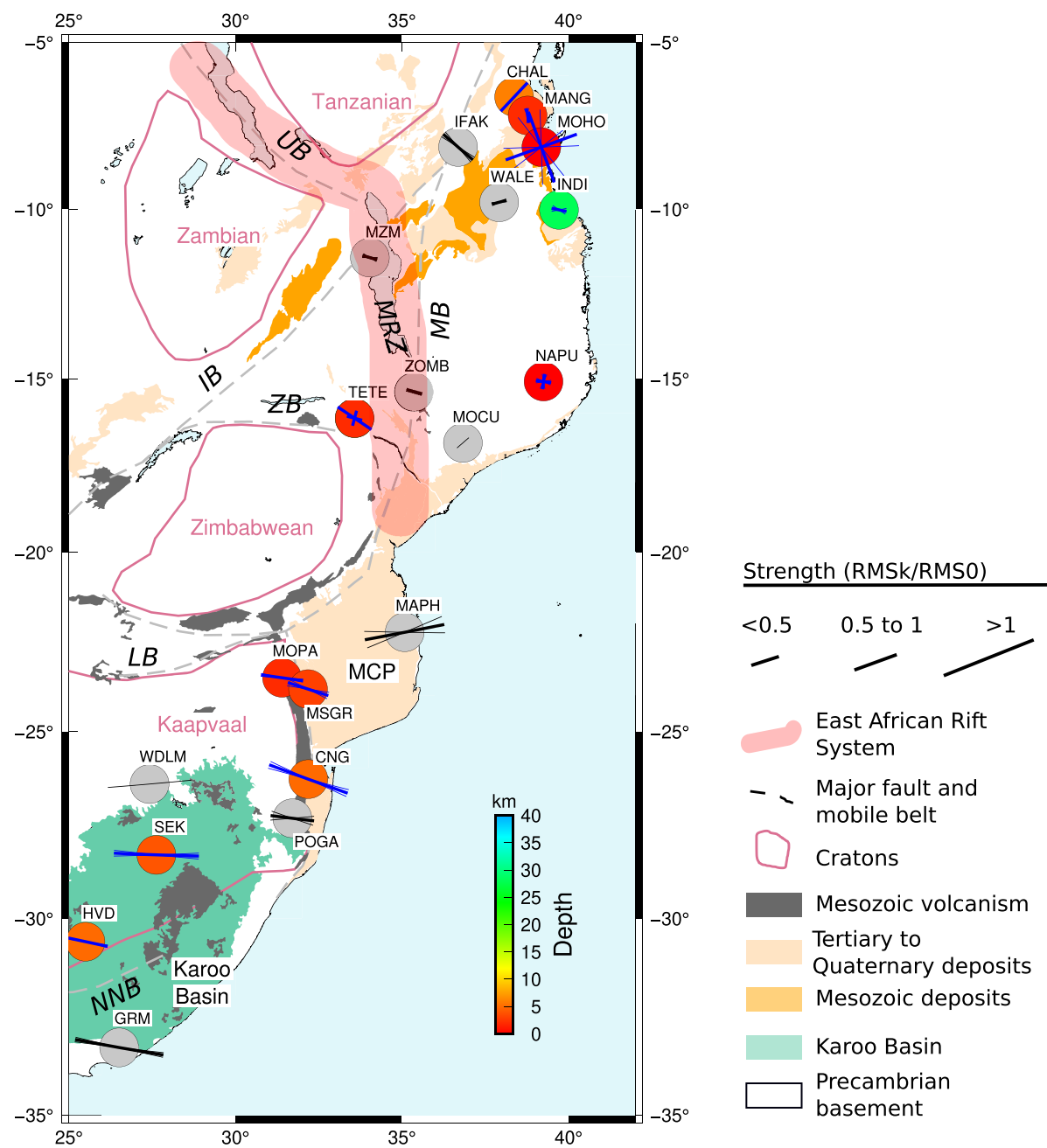

Figure 4. Simplified geology of Africa and estimated angle for the crust based on harmonic decomposition of receiver functions. A single bars represents an orientation from degree-1 harmonics: black for the strike of a dipping interface, blue for the strike of a plane normal to a dipping fast or slow axis of symmetry in case of anisotropy. Degree-2 orientations for horizontal anisotropy are represented by two blue bars, one is the azimuth of the fast or slow symmetry axis, the other is the strike of the plane normal to it. Bars are scaled according to the ratio of RMS amplitude over the crust between degree- $k$ and degree- 0 $\left(\mathrm{RMS}_{k} / \mathrm{RMS}_{0}\right)$. When the uncertainties are $<25^{\circ}$, a thick bar is framed with thinner blue bars representing the standard error range. When the uncertainties are $>25^{\circ}$, the orientation is given by a thin bar only. Estimated depth contrast is indicated by a coloured circle at each station except in case of dominant dipping isotropic contrast where depth is not estimated and circles are filled in grey.

can be noted. At stations MSGR and CNG where crustal anisotropy is dominant, looking at their rotated harmonics, a secondary source from a dipping isotropic interface can be suspected. At station MAPH, a relatively strong mid-crustal anisotropic contrast compared to the dominating dipping isotropic interface is clearly visible which greatly complicates the interpretation of the calculated orientation. On the remaining stations, secondary sources of anisotropy appear weak on rotated harmonics giving good confidence on the retrieved orientations.

One can observe that only stations located outside of the Karoo Basin and the Lebombo belt have dominant signals from dipping isotropic interfaces with only mild crustal anisotropy. The Karoo Basin is a foreland basin that opened parallel to the Cape Fold Belt in Mesozoic (Catuneanu et al. 2005; Lindeque et al. 2011). Succession of vertical movements and volcanic episodes might have contributed to the development of a complex geometry (e.g. Tankard et al. 2009; Dhansay et al. 2017) and strong lithological contrasts at depth (Braun et al. 2014). Our recovered $\mathrm{E}-\mathrm{W}$ strike for dipping interfaces are therefore consistent with the morphology and contours of the basin and likely reflect $\mathrm{E}-\mathrm{W}$ trending interface either dipping northward or southward.

On the other hand, at stations within the Karoo Basin and the Lebombo Belt, upper crustal seismic anisotropy is dominant despite the interferences mentioned above. Strong amplitudes on their degree-1 harmonics can be attributed to strong lithological contrasts between volcanic layers and surrounding sedimentary layers. Comparing harmonics components of stations HVD, SEK and MOPA with stations MSGR and CNG illustrates how a dipping isotropic source interferes with a seismic anisotropic source but gives confidence that seismic anisotropy characteristics are identical beneath all these five stations.

In the upper crust, seismic anisotropy is a good indicator of the current stress regime and arises from the alignment of cracks or fractures in the direction of maximal stress or from layering (Crampin 1994; Vergne et al. 2003). In eastern Africa, the EARS is responsible for a first-order E-W extensive stress field (e.g. Calais et al. 2006), while second-order ENE-WSW and WNW-ESE stress patterns might also be 


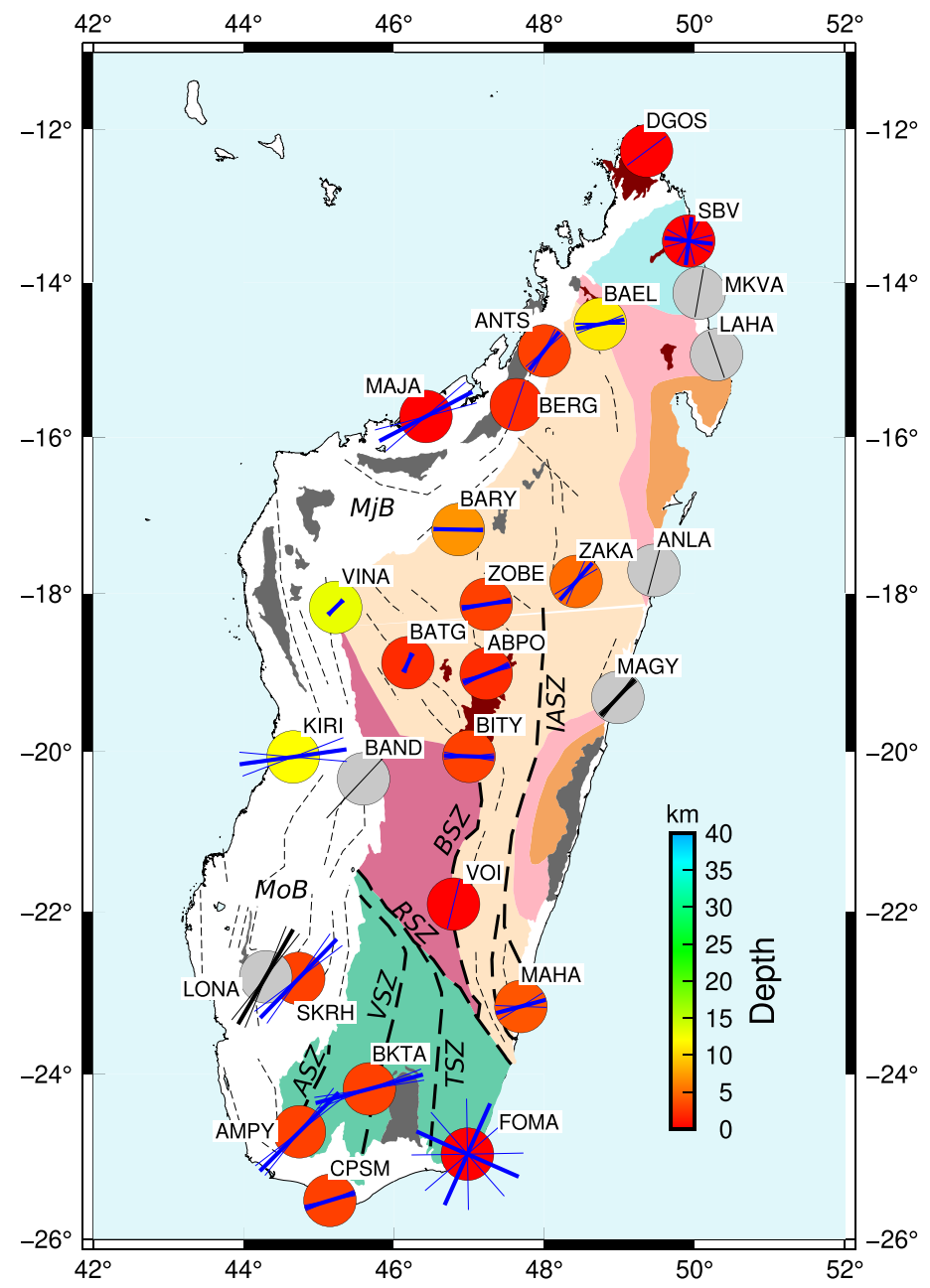

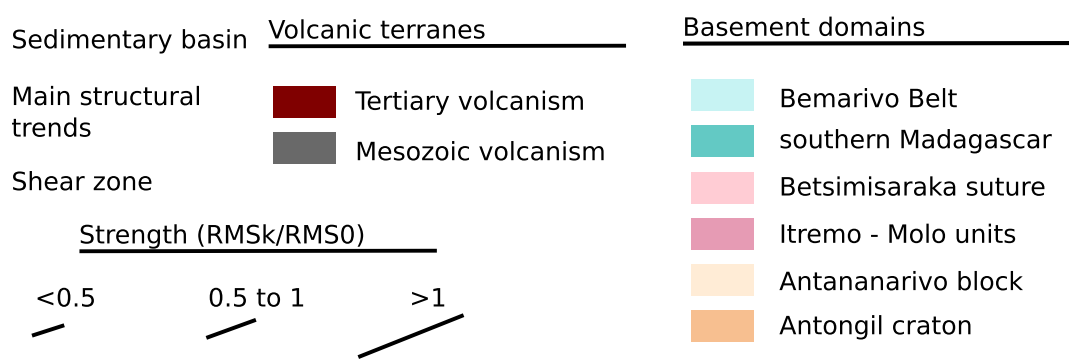

Figure 5. Same as Fig. 4 for Madagascar. The major shear zones are also represented; ASZ, Ampanihy shear zone; BSZ, Betsileo shear zone; IASZ, Ifanadina-Angavo shear zone; RSZ, Ranotsara shear zone; TSZ, Tranomaro shear zone; VSZ, Vorokafortra shear zone.

observed in some areas (Delvaux \& Barth 2010). In South Africa, which is almost aseismic, the stress regime indicates mainly normal faulting with the axis of the principal stress trending WNW-ESE to NNW-SSE (Delvaux \& Barth 2010). Our results indicate E-W orientations of the foliation plane which is perpendicular to the fast axis of symmetry. As suggested before by Adam \& Lebedev (2012) our measurements are therefore consistent with upper crustal seismic anisotropy generated by the alignment of cracks with N-S fast symmetry axis under an E-W stress regime. Upper crustal anisotropy might not be so strong in reality but be amplified in the Karoo Basin, the Limpopo Belt (Adam \& Lebedev 2012) and the Lebombo belt due to strong seismic contrasts between Karoo Traps and enclosing sediments. An alternative could be that seismic anisotropy is effectively stronger in these areas because they represent weaker zones where deformation tends to be concentrated.

In northern Mozambique and Tanzania dipping isotropic contrasts are dominant in the continental interior while anisotropy dominates in the upper crust along the coast. At two stations IFAK and WALE the signal from a dipping interface is very clear without any contamination from secondary sources. Given their location at the edges of sedimentary deposits their orientations possibly reflect the strike of the dipping isotropic contrast between these sediments and underlying basement. Three other stations ZOMB, MZM and MOCU are located over major structural belts and/or within Precambrian domains. ZOMB and MZM show similar NW-SE orientations which are normal to shear zones while the strike at MOCU is SW-NE. It is puzzling to see that the two stations located over the EARS (e.g. Fairhead \& Henderson 1977; Yang 
\& Chen 2008; Attanayake \& Foncesca 2016) give similar orientations, however, interferences from anisotropic contrasts can be observed and it is difficult to find any clear trend from them only. On each side of the southern EARS branch, stations NAPU and TETE are both located within the Precambrian domain. Their harmonic components suggest great complexities with several sources of azimuthally varying signal within the entire crustal range making also very difficult to draw any conclusion from these measurements. Finally for Africa, at the four stations close to the coast of Tanzania, our measurements also remain difficult to explain. Stations CHAL, MANG, MOHO and INDI all show very different orientations and their harmonics demonstrate an interplay between an upper crustal anisotropic source and a dipping isotropic contrast, consistent with their location at a continental margin. Northern Mozambique and southern Tanzania would therefore require a better coverage of seismic stations to capture the properties of seismic anisotropy in the upper crust.

\subsection{Dipping interfaces versus anisotropy in Madagascar}

In the Malagasy crust the first striking pattern in our results is the dominance of plunging crustal anisotropic contrasts in the island interior while only few dominant dipping isotropic contrasts are found along its eastern and western margins (Fig. 5).

Along the eastern margin of Madagascar, our measurements are dominated by N-S oriented strikes of dipping isotropic interfaces. At stations LAHA, MKVA and ANLA the dipping isotropic contrast is clearly dominating the harmonic signal with only weak secondary source of anisotropy visible. Only the harmonic components at station MAGY suggest the interplay of dipping isotropic and crustal anisotropic interfaces and could explain its strike slightly deviating from the orientation of the coastline. Considering that measurements at these four stations are representative of dipping interfaces and strike parallel to the shoreline, they are consistent with the abrupt separation of Madagascar and the India-Seychelles block in the late Cretaceous period (Reeves 2014; Andriampenomanana et al. 2017).

At stations located on the western Morondava and northwestern Mahajanga basins our measurements imply a clear trend of NE-SW orientations except for station KIRI where the dominant anisotropy is WSW-ENE. Harmonics components at this station reveal a strong anisotropic signal over the entire crust combined with a weaker amplitude isotropic dipping source. At LONA and BAND, stations where a dipping isotropic contrast is dominant, harmonics are suggestive of interferences with crustal anisotropic signals. At stations SKRH, VINA, MAJA, BERG and ANTS the presence of a dipping isotropic contrast can be suspected and thus may have contributed to cause a deviation in the measured angles. Combined effects of anisotropy and dipping isotropic contrasts are expected in such marginal basins. KIRI might therefore be the only station to give a good estimation of the orientation of crustal anisotropy. At the other stations the measured angles likely represent the averaged orientation between anisotropy and the basin's structural trends, which are dominated by crustal thinning and NNE-SSW faults inherited from its Jurassic rifting (Schandelmeier et al. 2004; Andriampenomanana et al. 2017). Along passive margins affected by extensions, seismic anisotropy might be recorded in the lithosphere, with a symmetry axis in the direction of extension (e.g. Vauchez et al. 2000; Lamarque \& Julia 2019). The N-S orientation of symmetry axis at the KIRI station is consistent with the N-S opening direction of Madagascar with respect to Africa in Jurassic. However our results are dominated by crustal anisotropy which likely recorded this phase of extension with more complexity than the mantle.

Over the Precambrian crystalline basement in the south of Madagascar where major shear zones strike through, there is another SW-NE visible trend in our measures except at station VOI where the foliation plane is oriented N-S. At VOI very weak amplitudes are observed on harmonics components but their rotation depicts two different sources of equal strength. The simplest explanation is that these harmonics reflect the upper crustal structure of the Betsileo shear zone. Stations AMPY, BKTA, CPSM, FOMA and MAHA do not directly sit on top of shear zones. They are all dominated by an upper crustal anisotropic signal with weaker secondary anisotropic sources but their harmonics all show also the typical signature of a dipping isotropic contrast. Therefore, as the stations located on the western margin of the island, orientations found at these southern stations are likely the result of the interplay of upper crustal anisotropy and a dipping structural contrast most likely N-S oriented shear zones in this area (Bertil \& Regnoult 1998; Andrianaivo \& Ramasiarinoro 2010; Kusky et al. 2010).

At first sight the strikes recovered at stations located on the Antananarivo domain are either SSW-NNE or WSW-ENE to E-W. As for VINA, there is clear interference between a dipping isotropic contrast and upper crustal anisotropy on harmonics of stations BATG, ZAKA. On the other hand at stations BITY, ABPO, ZOBE, BARY and further north BAEL, the upper crustal seismic anisotropic signal is clearly dominant although it appears still slightly affected by a dipping isotropic contrast. In the central part of Madagascar volcanics of the CMAP pierced through the Antananarivo block. Contrary to southern Africa, the homogeneity of our orientations at stations BITY, ABPO, ZOBE and BARY preclude any interferences from these volcanics on harmonic signals. Several studies suggest that the Malagasy crust is currently affected by E-W extension (Kusky et al. 2010; Rindraharisaona et al. 2013). As for the EARS, E-W extension in Madagascar could align crustal cracks leading to upper crustal seismic anisotropy with $\mathrm{N}-\mathrm{S}$ fast symmetry axis or E-W oriented foliation planes as recovered at the four above-mentioned stations located on the Antananarivo domain. But this likely also explains our observed azimuths at stations BAEL in the north of the island, KIRI over the western sedimentary basin and to a lesser extent BKTA in southern Madagascar. We therefore suggest that the calculated orientations from harmonic decomposition of receiver function at all the Malagasy stations reflect the interplay between inherited subsurface dipping isotropic contrasts and upper crustal seismic anisotropy generated by the E-W stress regime that currently affect the island. 


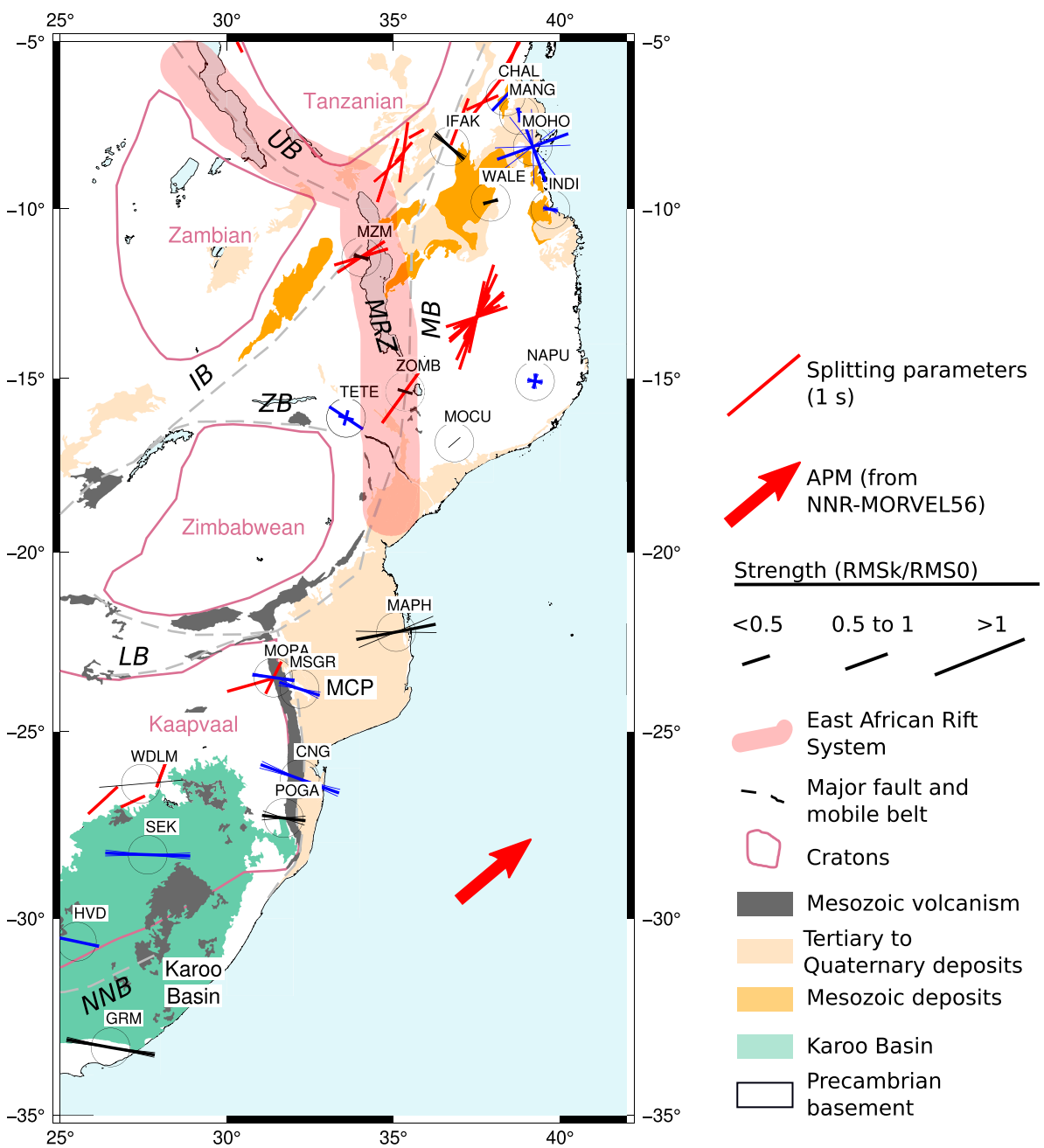

Figure 6. Comparison of azimuths obtained from our receiver function harmonics decomposition in the crust and from SKS splitting results (in red) in Africa. SKS splitting parameters were extracted from the shear wave splitting data base (Barruol et al. 2009).

\subsection{Comparison with SKS-splitting measurements}

If seismic anisotropy is present in the upper and lower crust, it might contribute to the apparent splitting of shear waves. Thus, to fully characterize the anisotropy in the mantle, SKS splitting measurements should take the contribution from the whole lithosphere into account.

Seismic anisotropy has been inferred in the mantle below southeastern Africa and Madagascar from SKS splitting measurements, some at the same seismic stations used in this study (Figs 6 and 7; Wüstefeld et al. 2009). Compared to receiver functions, the SKS phase is sensitive to the whole ray path into the mantle at lower frequencies and does not constrain the location of anisotropy at depth. Comparing our measurements with the SKS splitting parameters only allows to emphasize a possible impact or contamination of upper crustal anisotropy on those SKS measurements. This may occur under southern Africa where this study reveal clear evidence of strong crustal anisotropy oriented by the present day stress regime. These measurements are close to orientations recovered from SKS splittings which rises the question of how much crustal anisotropy has contributed to their azimuths and delay times.

The splitting parameters are quite complex under Madagascar, which lead Ramirez et al. (2018) to consider several sources of anisotropy in the lithosphere (frozen-in deformation) and in the asthenosphere (mantle flow). Fig. 7 shows that SKS orientations are mostly E-W in the Mahajanga basin, at least in the northern part of the island. Ramirez et al. (2018) proposed for the latter area that they could result from the interaction of an NE-oriented mantle flow (from the APM or from the African Superplume) with the southwards flow from the Comoros. As discussed above we suspect $\mathrm{N}-\mathrm{S}$ oriented fast axes of symmetry for the entire island which could play similar role as a Comoros southward mantle flow in deviating SKS from the orientation they acquired initially by the APM mantle flow. Over the Precambrian domain of the island and most specifically at the most central station ABPO, Paul \& Eakin (2017) reported mostly null measurements, which they attributed to a vertical mantle flux, consistent with the upwelling of the asthenosphere. Ramirez et al. (2018), reported an NW-SE orientation as being part of a rotating pattern around the CMAP and proposed that this could reflect the interaction of the APM-driven flow with the upwelling asthenosphere. In southern Madagascar, around the Ampanihy and Vorokafortra shear zones and particularly at station VOI, Reiss et al. (2016) also proposed NW-SE orientated fossil deformation in the lithosphere. We indeed observe a possible N-S trend of SKS orientations 

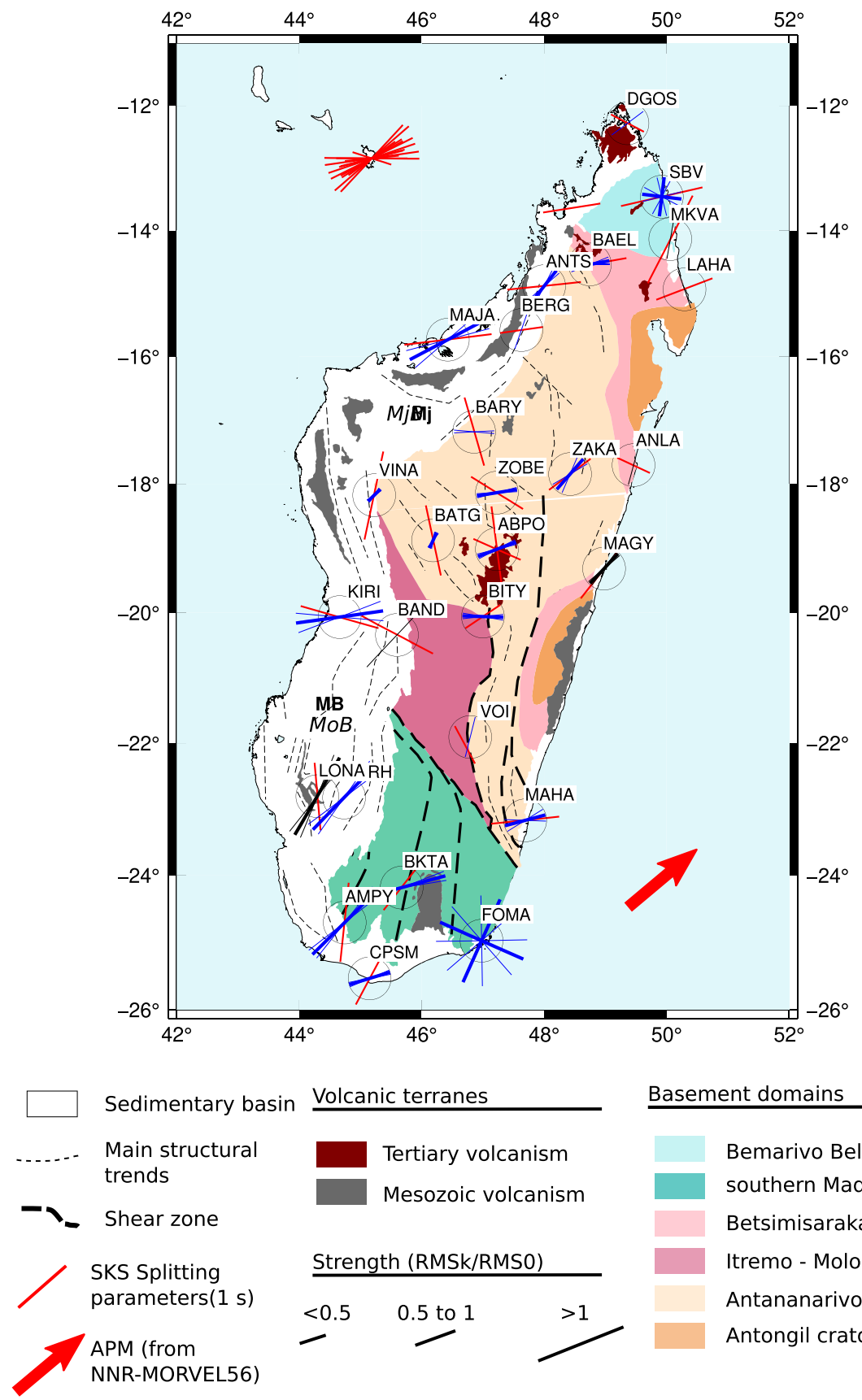

Volcanic terranes

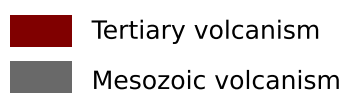

Strength (RMSk/RMSO)
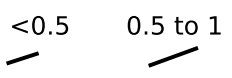

Basement domains

Bemarivo Belt

southern Madagascar

Betsimisaraka suture

Itremo - Molo units

Antananarivo block

Antongil craton

Figure 7. Same as Fig. 6 for Madagascar.

over these crystalline domains and thus question whether or not N-S oriented upper crustal anisotropy may have contributed significantly to these SKS splitting measurements.

\section{CONCLUSIONS}

This study reports on the decomposition of receiver functions into backazimuth harmonics for 48 stations located in southeastern Africa and Madagascar, around the Mozambique Channel. The method allows us to map the orientation of either azimuthal anisotropy or dipping isotropic velocity contrasts within the crust of these regions. Overall we show that azimuthally dependent signals are observed under all the stations at upper crustal depth. However, while some stations show a clear dominant source either isotropic or anisotropic, most reveal the interplay of these two types of periodic signals that consequently average or deviate our measurements of the orientations of the dominant source at each station.

In eastern South Africa our measures are generally oriented E-W. We interpret these results as dipping isotropic interfaces that dominate harmonics for stations located at the edge of the Karoo Basin, highlighting its structural morphology. for the remaining stations located over the basin interior and the Lembobo Belt, we propose that upper crustal seismic anisotropy sources in the alignment of cracks that build 
under the current stress regime as previously suggested from surface waves. Although this could also be valid for Mozambique and southern Tanzania we cannot draw such conclusion solely based on our results in these regions where refined or additional measurements are required.

In Madagascar, a similar scheme is observed where mostly dominant upper crustal seismic anisotropy conflict with structural dipping isotropic heterogeneities and give complex orientations although some general patterns might be observed in the different geological domains that compose the island. However, at some stations in each domain an upper anisotropic signal is dominant without being affected or only weakly by a dipping isotropic source. These few stations exhibit a clear $\mathrm{N}-\mathrm{S}$ fast axis of symmetry that can also be suspected at all remaining stations considering their measures have all been deviated to some amount by dipping isotropic interfaces. We propose that orientations obtained from receiver function harmonics in Madagascar can be attributed to both the present day regional $\mathrm{E}-\mathrm{W}$ stress regime already known in the island and dipping structural contrasts that locally prevail under each station.

Overall, comparing our results with SKS measures may highlight the influence of upper crustal seismic anisotropy on those orientations. Receiver functions harmonic decomposition appears also as insightful tool not only for imaging local, possibly inherited, subsurface heterogeneities but also current crustal stress at regional scale.

\section{ACKNOWLEDGEMENTS}

The data used in this study are freely available from seismological data centres as detailed hereinafter. We used the IRIS Web Services (https://service.iris.edu/) to download the following networks: (1) the AF (AfricaArray; Penn State University 2004), (2) the YH (AfricaArray SE Tanzania Basin Experiment; Nyblade 2010), (3) the XV (MACOMO; Wysession \& Wiens 2011) and (4) the II (IRIS/IDA; Scripps Institution of Oceanography 1986). Seismic data from the GEOSCOPE network (G; Institut de Physique du Globe de Paris \& Ecole Et Observatoire Des Sciences De La Terre De Strasbourg 1982) were downloaded from the RESIF data centre. Seismic data from the GE network (GE; GEOFON Data Center 1993) were obtained from the GEOFON data centre of the GFZ German Research Centre for Geosciences.

We used the open-source programs GMT 5.4.4 (Wessel et al. 2013), Python 3.7.0, Computer Programs in Seismology (Herrmann 2013), Raysum 1.2 (Frederiksen \& Bostock 2000) and Obspy (Beyreuther et al. 2010) to produce figures and to analyse and process the seismic data.

This work was supported by funding from Université Bretagne Loire (UBL) and Laboratoire d'Excellence LabexMer (ANR-10-LABX19), co-funded by a grant from the French government under the programme 'Investissements d'Avenir'. ME, GL and JJ acknowledge financial support from CAPES-COFECUB.

We thank Nicola Piana Agostinetti for precious helps on the methodology. We thank the Editor Ian Bastow, Frederik Tilmann and two anonymous reviewers for their constructive comments that greatly improved this manuscript.

\section{REFERENCES}

Adam, J.M.C. \& Lebedev, S., 2012. Azimuthal anisotropy beneath southern Africa from very broad-band surface-wave dispersion measurements, Geophys. J. Int., 191(1), 155-174.

Adimah, N.I. \& Padhy, S., 2020. Ambient noise Rayleigh wave tomography across the Madagascar island, Geophys. J. Int., 220(3), 1657-1676.

Andriampenomanana, F. et al., 2017. The structure of the crust and uppermost mantle beneath Madagascar, Geophys. J. Int., 210(3), 1525-1544.

Andrianaivo, L. \& Ramasiarinoro, V.J., 2010. Relation between regional lineament systems and geological structures: implications for understanding structural controls of geothermal system in the volcanic area of Itasy, Central Madagascar, in Proceedings World Geothermal Congress, pp. 25-30, Bali, Indonesia.

Attanayake, J. \& Fonseca, J.F., 2016. The intraplate $M_{\mathrm{w}} 7$ Machaze earthquake in Mozambique: improved point source model, stress drop, and geodynamic implications, J. Afr. Earth Sci., 117, 252-262.

Audet, P., 2015. Layered crustal anisotropy around the San Andreas fault near Parkfield, California, J. geophys. Res., 120(5), 3527-3543.

Bagley, B. \& Nyblade, A.A., 2013. Seismic anisotropy in eastern Africa, mantle flow, and the African superplume, Geophys. Res. Lett., 40(8), $1500-1505$.

Barruol, G. \& Mainprice, D., 1993. A quantitative evaluation of the contribution of crustal rocks to the shear-wave splitting of teleseismic SKS waves, Phys. Earth planet. Inter., 78(3-4), 281-300.

Barruol, G., Wuestfeld, A. \& Bokelmann, G., 2009. SKS-Splitting Database, Université de Montpellier, Laboratoire Géosciences.

Becker, T.W., 2008. Azimuthal seismic anisotropy constrains net rotation of the lithosphere, Geophys. Res. Lett., 35(5), doi:10.1029/2007GL032928.

Bertil, D. \& Regnoult, J.M., 1998. Seismotectonics of Madagascar, Tectonophysics, 294(1-2), 57-74.
Besairie, H., 1973. Carte géologique à 1/20000000 de Madagascar, Service Géologique de Madagaskara.

Beyreuther, M., Barsch, R., Krischer, L., Megies, T., Behr, Y. \& Wassermann, J., 2010. ObsPy: a Python toolbox for seismology, Seismol. Res. Lett., 81(3), 530-533.

Bianchi, I., Park, J., Piana Agostinetti, N. \& Levin, V., 2010. Mapping seismic anisotropy using harmonic decomposition of receiver functions: an application to Northern Apennines, Italy, J. geophys. Res., 115, B12317, doi:10.1029/2009JB007061.

Boness, N.L. \& Zoback, M.D., 2006. A multiscale study of the mechanisms controlling shear velocity anisotropy in the San Andreas Fault Observatory at Depth, Geophysics, 71(5), F131-F146.

Braun, J., Guillocheau, F., Robin, C., Baby, G. \& Jelsma, H., 2014. Rapid erosion of the Southern African Plateau as it climbs over a mantle superswell, J. geophys. Res., 119(7), 6093-6112.

Brownlee, S.J., Schulte-Pelkum, V., Raju, A., Mahan, K., Condit, C. \& Orlandini, O.F., 2017. Characteristics of deep crustal seismic anisotropy from a compilation of rock elasticity tensors and their expression in receiver functions, Tectonics, 36, 1835-1857.

Calais, E., Ebinger, C., Hartnady, C. \& Nocquet, J.M., 2006. Kinematics of the East African Rift from GPS and earthquake slip vector data, Geol. Soc. Lond., Spec. Publ., 259(1), 9-22.

Carlson, R.W. et al., 2000. Continental growth, preservation and modification in southern Africa, GSA Today, 10(2), 1-7.

Catuneanu, O., Wopfner, H., Eriksson, P.G., Cairncross, B., Rubidge, B.S., Smith, R.M.H. \& Hancox, P.J., 2005. The Karoo basins of south-central Africa, J. Afr. Earth Sci., 43(1-3), 211-253.

Chorowizc, J., 2005. The East African rift system, J. Afr. Earth Sci., 43(1-3), 379-410. 
Coffin, M.F. \& Rabinowitz, P.D., 1987. Reconstruction of Madagascar and Africa: evidence from the Davie fracture zone and Western Somali Basin, J. geophys. Res., 92(B9), 9385-9406.

Collins, A.S., 2006. Madagascar and the amalgamation of Central Gondwana, Gondwana Res., 9(1-2), 3-16.

Cossette, E., Audet, P., Schneider, D. \& Grasemann, B., 2016. Structure and anisotropy of the crust in the Cyclades, Greece, using receiver functions constrained by in situ rock textural data, J. geophys. Res., 121(4), 2661-2678.

Courgeon, S. et al., 2016. Growth and demise of Cenozoic isolated carbonate platforms: new insights from the Mozambique Channel seamounts (SW Indian Ocean), Mar. Geol., 380, 90-105.

Crampin, S., 1978. Seismic-wave propagation through a cracked solid: polarization as a possible dilatancy diagnostic, Geophys. J. Int., 53(3), 467496.

Crampin, S., 1994. The fracture criticality of crustal rocks, Geophys. J. Int., 118(2), 428-438.

Delvaux, D. \& Barth, A., 2010. African stress pattern from formal inversion of focal mechanism data, Tectonophysics, 482(1-4), 105-128.

Deville, E. et al., 2018. Active fault system across the oceanic lithosphere of the Mozambique Channel: implications for the Nubia-Somalia southern plate boundary, Earth planet. Sci. Lett., 502, 210-220.

Dhansay, T., Navabpour, P., de Wit, M. \& Ustaszewski, K., 2017. Assessing the reactivation potential of pre-existing fractures in the southern Karoo, South Africa: evaluating the potential for sustainable exploration across its Critical Zone, J. Afr. Earth Sci., 134, 504-515.

Domingues, A., Silveira, G., Ferreira, A.M., Chang, S.J., Custódio, S. \& Fonseca, J.F., 2016. Ambient noise tomography of the East African Rift in Mozambique, Geophys. J. Int., 204(3), 1565-1578.

Ebinger, C.J., Rosendahl, B.R. \& Reynolds, D.J., 1987. Tectonic model of the Malawi rift, Africa, Tectonophysics, 141(1-3), 215-235.

Fairhead, J.D. \& Henderson, N.B., 1977. The seismicity of southern Africa and incipient rifting, Tectonophysics, 41(4), T19-T26.

Frederiksen, A.W. \& Bostock, M.G., 2000. Modelling teleseismic waves in dipping anisotropic structures, Geophys. J. Int., 141(2), 401-412.

Gao, S., Davis, P.M., Liu, H., Slack, P.D., Zorin, Y.A., Mordvinova, V.V., Kozhevnikov, V.M. \& Meyer, R.P., 1994. Seismic anisotropy and mantle flow beneath the Baikal rift zone, Nature, 371, 149-151.

GEOFON Data Centre, 1993. GEOFON Seismic Network, Deutsches GeoForschungsZentrum GFZ.

Girardin, N. \& Farra, V., 1998. Azimuthal anisotropy in the upper mantle from observations of $P$-to- $S$ converted phases: application to southeast Australia, Geophys. J. Int., 133, 615-629.

Herrmann, R.B., 2013. Computer programs in seismology: an evolving tool for instruction and research, Seismol. Res. Lett., 84, 1081-1088.

Institut De Physique Du Globe De Paris \& Ecole Et Observatoire Des Sciences De La Terre De Strasbourg, 1982. GEOSCOPE, French Global Network of broad band seismic stations, Institut de physique du globe de Paris (IPGP), Université de Paris, https://doi.org/10.18715/GEOSCOPE.G

Kennett, B.L.N. \& Engdahl, E.R. 1991. Traveltimes for global earthquake location and estimation, Geophys. J. Int., 105, 429-465.

Kusky, T.M., Toraman, E., Raharimahefa, T. \& Rasoazanamparany, C., 2010. Active tectonics of the Alaotra-Ankay Graben System, Madagascar: possible extension of Somalian-African diffusive plate boundary? Gondwana Res., 18(2-3), 274-294.

Lamarque, G. \& Julià, J., 2019. Lithospheric and sublithospheric deformation under the Borborema Province of northeastern Brazil from receiver function harmonic stripping, Solid Earth, 10(3), 893-905.

Lamarque, G. \& Piana Agostinetti, N., 2020. Modeling of anisotropy in the lithosphere and asthenosphere for real Earth cases: a critical assessment of the impact on SKS measurements, J. geophys. Res., 125, e2019JB018978.

Langston, C.A., 1977. The effect of planar dipping structure on source and receiver responses for constant ray parameter, Bull. seism. Soc. Am., 67(4), $1029-1050$

Laske, G., Masters, G., Ma, Z. \& Pasyanos, M., 2013. Update on CRUST1. 0 - a 1-degree global model of Earth's crust, in EGU General Assembly, Vienna, Austria, EGU2013-2658.
Leinweber, V.T. \& Jokat, W., 2011. Is there continental crust underneath the northern Natal Valley and the Mozambique Coastal Plains? Geophys. Res. Lett., 38(14), L14303. doi:10.1029/2011GL047659.

Levin, V. \& Park, J., 1997a. Crustal anisotropy in the Ural Mountains Foredeep from teleseismic receiver functions, Geophys. Res. Lett., 24(11), 1283-1286.

Levin, V. \& Park, J., 1997b. P-SH conversions in a flat-layered medium with anisotropy of arbitrary orientation, Geophys. J. Int., 131(2), 253-266.

Ligorria, J.P. \& Ammon, C.J., 1999. Iterative deconvolution and receiverfunction estimation, Bull. seism. Soc. Am., 89(5), 1395-1400.

Lindeque, A., de Wit, M.J., Ryberg, T., Weber, M. \& Chevallier, L., 2011. Deep crustal profile across the southern Karoo Basin and Beattie Magnetic Anomaly, South Africa: an integrated interpretation with tectonic implications, South Afr. J. Geol., 114(3-4), 265-292.

Martelat, J.E., Lardeaux, J.M., Nicollet, C. \& Rakotondrazafy, R., 2000. Strain pattern and late Precambrian deformation history in southern Madagascar, Precambrian Res., 102(1-2), 1-20.

Mazzullo, A., Stutzmann, E., Montagner, J.P., Kiselev, S., Maruya, S., Barruol, G. \& Sigloch, K., 2017. Anisotropic tomography around La Réunion Island from Rayleigh waves, J. geophys. Res., 122(11), 9132-9148.

Moulin, M. et al., 2019. Gondwana breakup: messages from the North Natal Valley, Terra Nova, 32, 205-214.

Nguuri, T.K., Gore, J., James, D.E., Webb, S.J., Wright, C., Zengeni, T.G., Gwavava, O. \& Snoke, J.A., Kaapvaal Seismic Group., 2001. Crustal structure beneath southern Africa and its implications for the formation and evolution of the Kaapvaal and Zimbabwe cratons, Geophys. Res. Lett., 28(13), 2501-2504.

Nyblade, A., 2010. AfricaArray SE Tanzania Basin Experiment, International Federation of Digital Seismograph Networks.

Park, J. \& Levin, V., 2016. Anisotropic shear zones revealed by backazimuthal harmonics of teleseismic receiver functions, Geophys. J. Int., 207(2), 1216-1243.

Paul, J.D. \& Eakin, C.M., 2017. Mantle upwelling beneath Madagascar: evidence from receiver function analysis and shear wave splitting, J. Seismol., 21(4), doi:10.1007/s10950-016-9637-x.

Pearson, D.G., Carlson, R.W., Shirey, S.B., Boyd, F.R. \& Nixon, P.H., 1995. Stabilisation of Archaean lithospheric mantle: a ReOs isotope study of peridotite xenoliths from the Kaapvaal craton, Earth planet. Sci. Lett., 134(3-4), 341-357.

Peng, X. \& Humphreys, E.D., 1997. Moho dip and crustal anisotropy in northwestern Nevada from teleseismic receiver functions, Bull. seism. Soc. Am., 87(3), 745-754.

Penn State University, 2004. AfricaArray, International Federation of Digital Seismograph Networks.

Piana Agostinetti, N., Park, J. \& Pio Lucente, F., 2008. Mantle wedge anisotropy in Southern Tyrrhenian Subduction Zone (Italy), from receiver function analysis, Tectonophysics, 462(1-2), 35-48.

Pratt, M.J. et al., 2017. Shear velocity structure of the crust and upper mantle of Madagascar derived from surface wave tomography, Earth planet. Sci. Lett., 458, 405-417.

Ramirez, C., Nyblade, A., Wysession, M.E., Pratt, M., Andriampenomanana, F. \& Rakotondraibe, T., 2018. Complex seismic anisotropy in Madagascar revealed by shear wave splitting measurements, Geophys. J. Int., 215(3), $1718-1727$.

Reed, C.A., Liu, K.H., Yu, Y. \& Gao, S.S., 2017. Seismic anisotropy and mantle dynamics beneath the Malawi Rift Zone, East Africa, Tectonics, 36(7), 1338-1351.

Reeves, C., 2014. The position of Madagascar within Gondwana and its movements during Gondwana dispersal, J. Afr. Earth Sci., 94, 45-57.

Reiss, M.C., Rümpker, G., Tilmann, F., Yuan, X., Giese, J. \& Rindraharisaona, E.J., 2016. Seismic anisotropy of the lithosphere and asthenosphere beneath southern Madagascar from teleseismic shear wave splitting analysis and waveform modeling, J. geophys. Res., 121(9), 66276643.

Rindraharisaona, E.J., Guidarelli, M., Aoudia, A. \& Rambolamanana, G., 2013. Earth structure and instrumental seismicity of Madagascar: implications on the seismotectonics, Tectonophysics, 594, 165-181. 
Savage, M.K., 1998. Lower crustal anisotropy or dipping boundaries? Effects on receiver functions and a case study in New Zealand, J. geophys. Res., 103(B7), 15 069-15087.

Savage, M.K., 1999. Seismic anisotropy and mantle deformation: what have we learned from shear wave splitting? Rev. Geophys., 37(1), $65-106$

Schandelmeier, H., Bremer, F. \& Holl, H.G., 2004. Kinematic evolution of the Morondava rift basin of SW Madagascar-from wrench tectonics to normal extension, J. Afr. Earth Sci., 38(4), 321-330.

Schmitz, M.D., Bowring, S.A., de Wit, M.J. \& Gartz, V., 2004. Subduction and terrane collision stabilize the western Kaapvaal craton tectosphere 2.9 billion years ago, Earth planet. Sci. Lett., 222(2), 363-376.

Schulte-Pelkum, V. \& Mahan, K.H., 2014. A method for mapping crustal deformation and anisotropy with receiver functions and first results from USArray, Earth planet. Sci. Lett., 402, 221-233.

Schulte-Pelkum, V., Ross, Z.E., Mueller, K. \& Ben-Zion, Y., 2020. Tectonic inheritance with dipping faults and deformation fabric in the brittle and ductile southern California crust, J. geophys. Res., 125, e2020JB019525, doi:10.1029/2020JB019525

Scripps Institution of Oceanography, 1986. IRIS/IDA Seismic Network, International Federation of Digital Seismograph Networks.

Sherrington, H.F., Zandt, G. \& Frederiksen, A., 2004. Crustal fabric in the Tibetan Plateau based on waveform inversions for seismic anisotropy parameters, J. geophys. Res., 109(B2), doi:10.1029/2002JB002345.

Shiomi, K. \& Park, J., 2008. Structural features of the subducting slab beneath the Kii Peninsula, central Japan: seismic evidence of slab segmentation, dehydration, and anisotropy, J. geophys. Res., 113(B10), B10318, doi:10.1029/2007JB005535.

Silver, P.G. \& Chan, W.W., 1988. Implications for continental structure and evolution from seismic anisotropy, Nature, 335(6185), 34-39.

Silver, P.G. \& Chan, W.W., 1991. Shear wave splitting and subcontinental mantle deformation, J. geophys. Res., 96(B10), $16429-16454$.

Silver, P.G., Fouch, M.J., Gao, S.S. \& Schmitz, M., \& Kaapvaal Seismic Group, 2004. Seismic anisotropy, mantle fabric, and the magmatic evolution of Precambrian southern, Africa, South Afr. J. Geol., 107(1-2), $45-58$.

Silver, P.G., Gao, S.S. \& Liu, K.H., Kaapvaal Seismic Group, 2001. Mantle deformation beneath southern Africa, Geophys. Res. Lett., 28(13), 2493-2496.

Stankiewicz, J., Chevrot, S., van der Hilst, R.D. \& de Wit, M.J., 2002. Crustal thickness, discontinuity depth, and upper mantle structure beneath southern Africa: constraints from body wave conversions, Phys. Earth planet. Inter., 130(3-4), 235-251.
Tankard, A., Welsink, H., Aukes, P., Newton, R. \& Stettler, E., 2009. Tectonic evolution of the Cape and Karoo basins of South Africa, Mar. Pet Geol., 26(8), 1379-1412.

Torsvik, T.H., Tucker, R.D., Ashwal, L.D., Eide, E.A., Rakotosolofo, N.A. \& De Wit, M.J., 1998. Late Cretaceous magmatism in Madagascar: palaeomagnetic evidence for a stationary Marion hotspot, Earth planet. Sci. Lett., 164(1-2), 221-232.

Tucker, R.D., Roig, J.Y., Moine, B., Delor, C. \& Peters, S.G., 2014. A geological synthesis of the Precambrian shield in Madagascar, J. Afr. Earth Sci., 94, 9-30.

Vauchez, A., Tommasi, A., Barruol, G. \& Maumus, J., 2000. Upper mantle deformation and seismic anisotropy in continental rifts, Phys. Chem. Earth, Part A., 25(2), 111-117.

Vergne, J., Wittlinger, G., Farra, V. \& Su, H., 2003. Evidence for upper crustal anisotropy in the Songpan-Ganze (northeastern Tibet) terrane, Geophys. Res. Lett., 30(11), doi:10.1029/2002GL016847.

Vinnik, L., Green, R.W.E. \& Nicolaysen, L.O., 1995. Recent deformations of the deep continental root beneath southern Africa, Nature, 375, 50-52.

Vinnik, L.P., 1977. Detection of waves converted from P to SV in the mantle, Phys. Earth planet. Inter, 15(1), 39-45.

Vinnik, L.P., Makeyeva, L.I., Milev, A. \& Usenko, A.Y., 1992. Global patterns of azimuthal anisotropy and deformations in the continental mantle, Geophys. J. Int., 111(3), 433-447.

Watkeys, M.K., 2002. Development of the Lebombo rifted volcanic margin of southeast Africa, in Volcanic Rifted Margins, Vol. 362, pp. 27-46, Menzies, M.A., Klemperer, S.L., Ebinger, C.J. \& Baker, J., eds, Geological Society of America.

Watts, A.B., 2001. Gravity anomalies, flexure and crustal structure at the Mozambique rifted margin, Mar. Pet. Geol., 18(4), 445-455.

Wessel, P., Smith, W.H., Scharroo, R., Luis, J. \& Wobbe, F., 2013. Generic mapping tools: improved version released, EOS, Trans. Am. geophys. Un., 94(45), 409-410.

Wysession, M. \& Wiens, D., 2011. Investigation of Sources of Intraplate Volcanism Using PASSCAL Broadband Instruments in Madagascar, the Comores, and Mozambique, International Federation of Digital Seismograph Networks.

Wüstefeld, 2009. Physics of the Earth and Planetary Interiors, 198-212, doi:10.1016/j.pepi.2009.05.006, 00319201.

Yang, Z. \& Chen, W.P., 2008. Mozambique earthquake sequence of 2006: high-angle normal faulting in southern Africa, J. geophys. Res., 113(B12), doi:10.1029/2007JB005419.

Zhu, L. \& Kanamori, H., 2000. Moho depth variation in southern California from teleseismic receiver functions, J. geophys. Res., 105(B2), 2969-2980.

\section{SUPPORTING INFORMATION}

Supplementary data are available at $G J I$ online.

Figure S1. Model (a) and RF synthetics (b) used to test the effect of noise and azimuthal coverage on the uncertainty of the harmonic decomposition method. In model (a), the anisotropy is 6 per cent and the fast axis trends $\mathrm{N} 60^{\circ}$ and plunges of $30^{\circ}$. Polarity reversal are clearly visible in the transverse RF at $60^{\circ}$ and $240^{\circ}$ (b). (c) and (d) are respectively as in Figs 2 and 3 the resulting harmonics and rotated harmonics. Figure S2. Effect of noise and azimuthal coverage on the harmonic decomposition method. (a) The evolution of the estimated angle (mean of the 500 realizations, top panel) and of the uncertainty on the angle sigma (standard deviation of the 500 realizations, bottom panel) as a function of the azimuthal gap/number of bins, in case where no noise was added to the synthetic RFs. (b) The same as (a) when noise was added to the synthetic RFs. In both case, the tests were proceed for randomly chosen bins (dashed lines) and focused azimuthal gap (dotted lines).

Figure S3. For each station, radial (a) and transverse (b) receiver functions stacked in backazimuth bins of $10^{\circ}$ without overlap; (c) resulting harmonics corresponding to the degrees $k=0(A), k=1\left(B_{1}, C_{1}\right)$ and $k=2\left(B_{2}, C_{2}\right)$; (d) rotated harmonics according to angle provided in Table 1: degree $k=0(A)$ is repeated then rotated harmonics for degree $k=1\left(\mathrm{Br}_{1}, \mathrm{Cr}_{1}\right)$ and $k=2\left(\mathrm{Br}_{2}, \mathrm{Cr}_{2}\right)$.

Table S2. Results and uncertainties of the $h-k$ stacking method.

SupportingInformation_TsangHinSun_Anisotropy_Mar2021_GJI.pdf

Table1.csv

Please note: Oxford University Press is not responsible for the content or functionality of any supporting materials supplied by the authors. Any queries (other than missing material) should be directed to the corresponding author for the paper. 